\title{
Intertemporal deprivation in rural china: income and nutrition
}

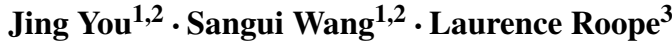

Received: 10 June 2015 / Accepted: 11 April 2017 / Published online: 5 June 2017

(C) The Author(s) 2017. This article is an open access publication

\begin{abstract}
We analyse intertemporal poverty in two important dimensions - income and nutrition - in less developed northwest China during 2000-2004. Household intertemporal deprivations in these dimensions are estimated using measures which are sensitive to the precise sequence in which poor and non-poor spells occur. A generalised recursive selection model is then proposed to investigate the determinants of intertemporal deprivation in each dimension, allowing for the possibility that correlated unobservables drive the dual deprivations. Improvement in agricultural production is crucial for reducing both dimensions of intertemporal deprivation. We find evidence suggestive of intertemporal income-nutrition poverty traps. Higher labour productivity, especially in agriculture rather than local off-farm activities or out-migration, holds much potential for breaking the vicious circle. Agricultural innovation and mechanisation, regarded by the government as indispensable, yield mixed outcomes for alleviating intertemporal multi-dimensional deprivations.
\end{abstract}

Electronic supplementary material The online version of this article (doi:10.1007/s10888-017-9352-z) contains supplementary material, which is available to authorized users.

Sangui Wang

wangsg@ruc.edu.cn

Jing You

jing.you@ruc.edu.cn

Laurence Roope

laurence.roope@dph.ox.ac.uk

1 School of Agricultural Economics and Rural Development, Renmin University of China, 59 Zhongguancun Street, Beijing, 100872 China

2 China Anti-Poverty Research Institute, Renmin University of China, 59 Zhongguancun Street, Beijing, 100872 China

3 Health Economics Research Centre, Nuffield Department of Population Health, University of Oxford, Old Road Campus, Oxford, OX3 7LF, UK 
Keywords Intertemporal poverty $\cdot$ Multi-dimensional poverty $\cdot$ Rural China

\section{Introduction}

Over the last few years, two major developments in the way poverty is conceptualised and measured stand out. These regard, respectively, poverty's multi-dimensionality and its dynamic nature over time. Developing measurement techniques which appropriately capture these important aspects of poverty has been a very active area of research lately. The vast majority of contributions though have focused on capturing either the multi-dimensional aspect, or the temporal aspect, and have not attempted to deal with both simultaneously.

With regard to multidimensionality, notable contributions have been made by many authors including, among others, Tsui (2002), Bourguignon and Chakravarty (2003), Atkinson (2003) and Alkire and Foster (2011a). ${ }^{1}$ Despite the advances, there remains quite a fundamental point of difference in the literature. In one camp are those, such as Alkire and Foster (2011b), who argue for the value of identifying the poor by considering the joint distribution of deprivations, and of using a methodology which can indicate changes over time in a unified and internally consistent framework. In the other camp are those such as Ravallion (2011), who, citing difficulties in choosing which dimensions to include, and how they should be weighted, argues that we should "... aim for a credible set of "multiple indices" rather than a single "multidimensional index." (p. 247).

As well as the importance of multidimensionality, it is also increasingly recognised that measuring a "snapshot" of poverty, at a single point in time, or even consecutive "snapshots", is inadequate for capturing poverty as people experience it. ${ }^{2}$ It seems clear that the way in which poor spells are interspersed with non-poor spells, and the overall proportion of poor spells and their intensity must play an important role. Yet there is scope for a variety of views on how best to aggregate such information and there are a fast growing number of methodologies. These include Foster (2009), who accounts for the detrimental impact of spending a high proportion of time in poverty on the overall level of chronic poverty; Hoy and Zheng (2011), who account, among other things, for the particularly damaging impact of poverty early in life on capability or human capital formation, resulting in low long-term wellbeing, in the context of lifetime poverty; Bossert et al. (2012), who attach importance to the debilitating impact of prolonged periods spent in poverty, and Dutta et al. (2013), who incorporate also the mitigating impact that affluent spells might have on subsequent periods of poverty. ${ }^{3}$

While much progress has been made in measuring poverty both across dimensions, and over time, attempts to simultaneously account for multi-dimensional and intertemporal aspects of poverty in its measurement are in their infancy. The few such studies include Alkire et al. (2013), who combine the counting approach of Foster (2009) over time, with

\footnotetext{
${ }^{1}$ The latter has been especially influential in empirical work and provides a suite of indices that have been adopted to monitor multi-dimensional poverty by a number of national governments. Since 2010, a special case of these indices (Alkire and Santos, 2011) has been reported in the UNDP's Human Development Report.

${ }^{2}$ It also tends to underestimate the number of people affected by poverty; a much greater proportion of people may experience poverty when observed over a longer time frame (Baulch and Hoddinott, 2000).

${ }^{3}$ This list is far from exhaustive. Other notable studies include, among others, Calvo and Dercon (2009), Zheng (2011) and Mendola and Busetta (2012, 2013).
} 
the counting approach across dimensions of Alkire and Foster (2011a), and D'Ambrosio (2013). The approach taken in the latter study begins by calculating intertemporal poverty in each dimension of interest separately and identifying individuals as multi-dimensionally poor if they experience functioning failure in at least one dimension, as in Atkinson (2003). Then, in the spirit of Alkire and Foster (2011a), a weighted average of all dimensions is used as an aggregate index for multi-dimensional intertemporal poverty. ${ }^{4}$

The contributions of this study are both empirical and methodological. Empirically, our interest is in shedding light on poverty, and its possible determinants, in two poor regions of rural northwest China - Gansu and Inner Mongolia. Using the measures of Dutta et al. (2013), we capture poverty as intertemporal deprivations in two important aspects of wellbeing - income and nutrition. ${ }^{5}$

There have been relatively few studies of income poverty in rural China which explicitly account for its temporal aspect. The studies that have been conducted have been largely concerned with decomposing total poverty into chronic and transient components. Jalan and Ravallion (1998) and McCulloch and Calandrino (2003), estimated overall poverty, at a household level, for rural Sichuan province, in southwest China, in the second half of the 1980s and the first half of the 1990s, respectively, and decomposed it into chronic and transient components. In these studies, total household intertemporal poverty is given by the mean per period poverty gap, raised to some power. The chronic poverty component is obtained by comparing the mean income over time with the poverty lines, so that a household is chronically poor only if their mean income lies below this. More recently, Duclos et al. (2010) built on these approaches to develop a framework in which total societal intertemporal poverty depends not only on mean poverty gaps, over time and across individuals, but is exacerbated by variability in poverty over time, both at an individual level, and with regard to inequality across individuals. Their approach was then applied to 82 villages in nine Chinese provinces (Anhui, Gansu, Guangdong, Henan, Hunan, Jiangsu, Jilin, Shanxi, and Sichuan).

The theoretical literature on measuring intertemporal poverty has recently reached quite a high level of sophistication, accounting, as described above, for individual poverty trajectories; the effect of the sequencing of poor and non-poor periods on an individual's overall intertemporal poverty. We apply poverty indices proposed by Dutta et al. (2013) to a sample of Chinese rural households. These measures have a number of appealing features. They are sensitive to (i) orders of poverty transitions; (ii) the length of poor and non-poor spells; as well as more standard concerns such as the depth of poverty when poor. ${ }^{6}$ These measures have been applied empirically to data for Great Britain (Roope and Peters, 2013) and for a number of countries in the European Union (D'Ambrosio, 2013). To the best of our knowledge, this is the first study which applies these recent techniques in a developing country context; indeed most, if not all, existing applications of recent intertemporal poverty measures are for developed countries (e.g., ibid; Gradín et al. 2012). For rural China, there has been no assessment of households' intertemporal poverty profiles which takes into account dynamic factors such as those outlined above.

\footnotetext{
${ }^{4}$ The weights are determined according to European respondents' perceptions of the relative importance of each welfare dimension.

${ }^{5}$ We do not, however, endeavour to develop an overall index of multi-dimensional intertemporal poverty, but estimate intertemporal deprivation in each dimension. In this sense, our approach might be interpreted as being in the spirit of Ravallion (2011).

${ }^{6} \mathrm{~A}$ special case of the measures also attaches some importance to the extent of affluence when not poor.
} 
It is widely recognised that the poor in the developing world not only suffer from income or consumption shortfalls, but also face a many-faceted deprivation space encompassing nutrition, health, education and various poor living conditions. Recent examples in a Chinese context include Labar and Bresson (2011), who study multi-dimensional poverty in rural China from 1991 to 2006, and Ray and Mishra (2012), who make comparisons between China, India and Vietnam. This study adds to this literature on multi-dimensionality of deprivations too, by exploiting a balanced household panel with annual waves from 2000 to 2004, which contains data on income and nutrition. We use these data to provide the first empirical estimates of household intertemporal deprivation in rural China, in these important dimensions. In so doing, we unearth evidence consistent with a possible intertemporal nutrition-income poverty trap. The conventional nutrition-income trap has been well-established according to the nutrition-based efficient wage hypothesis: higher wages allow households to invest more income in health and nutrition (e.g., Leibenstein, 1957; Bliss and Stern, 1978; Dasgupta and Ray, 1986, 1987; Strauss and Thomas, 1998). Evaluating income and nutrition poverty over a longer term sheds greater light on who are truly the poorest in these dimensions. This, in turn, enables better estimates of the correlation between deprivations in the two dimensions.

Having estimated the extent of intertemporal deprivations in two dimensions, we propose a novel method for jointly estimating their determinants - and this is the paper's central contribution to the literature. We propose a methodological framework, of general applicability, that takes into account the household unobservables which jointly determine various dimensions of wellbeing, and possible interdependence between observed deprivation outcomes in different dimensions. In this sense, our approach goes some way towards reconciling the strands of literature on multi-dimensional and intertemporal poverty. Our approach allows for the realistic possibility that the factors which allow us to "observe" deprivation outcomes, in the sense that a household is below the deprivation threshold in at least one time period and one dimension, may differ from the factors that, conditional upon this, determine the overall severity of deprivation in one or more dimensions, over the full period of analysis. Our method also allows for the (also realistic) possibility that the unobserved household-specific determinants of deprivation in each dimension are correlated. This empirical model can easily be applied to other developing countries where panel data are available.

We find that the correlation between income and nutrition deprivations is high, consistent with a poverty trap hypothesis in an intertemporal context. Our results also suggest that those residing in Gansu, relying on circular migration as their main livelihood and not having any family members belonging to ethnic minorities, are poorer intertemporally in both dimensions than their counterparts in Inner Mongolia, who make a living by agriculture or local non-agricultural production and have at least one family member from an ethnic minority. ${ }^{7}$ In the early stages of development, when agricultural production is the major component of household livelihood, agricultural development, in terms of increased labour productivity, bigger farm sizes and investment in productive assets, appears to hold much potential for alleviating both intertemporal income and nutritional deprivation. However,

\footnotetext{
${ }^{7}$ This finding is context specific for Inner Mongolia where ethnic minorities are richer compared with those in other parts of China, as their livelihood arrangement is a mixture of both agriculture and husbandry and the region is resource-rich. Nevertheless, ethnic minorities in China are, on average, poorer than the ethnic majority Han people. Section 3 gives detailed statistics for the two sample provinces.
} 
China's long exercised poverty alleviation policy in terms of investment in village infrastructures appears not to contribute to intertemporal poverty reduction, at least in the short-term, and the recent promotion of agricultural mechanisation would yield mixed outcomes.

This paper proceeds as follows. A theoretical framework for measuring dimensionspecific intertemporal deprivation, and our multi-dimensional generalised selection model, are described in Section 2. The dataset is discussed in Section 3. Results are presented in Section 4, while Section 5 concludes with possible suggestions to inform current policy.

\section{Measuring intertemporal poverty and estimating its determinants}

\subsection{Measuring intertemporal deprivation}

A household has a poverty profile, in a given dimension of attainment (here, income or caloric intake) given by $\mathbf{p}=\left(p_{1}, \cdots, p_{T}\right) \in[0,1]^{T}$, where $p_{t}$ indicates the household's "snapshot" poverty level at time $t$ as indicated by a normalized poverty gap from a poverty line $z .{ }^{8}$ As usual, therefore, $p_{t}=1$ indicates the maximum possible level of deprivation in period $t$ (no income, or no nutrition), while $p_{t}=0$ indicates that the household is non-poor.

We apply Dutta et al.'s (2013) unidimensional intertemporal poverty measures to each of our two dimensions to estimate the respective intertemporal deprivations. Following Dutta et al. (2013), an intertemporal poverty measure is a function which assigns to an individual's (or household's) poverty profile, in the given dimension, a non-negative number, i.e. $P: \bigcup_{T \in \mathbb{N}}[0,1]^{T} \longrightarrow \mathbb{R}_{+}$. Dutta et al. (2013) proposed and provided axiomatic characterisations for two classes of measures, their 'constant-relative affluence-dependent' intertemporal poverty measure $P_{R}$, and their 'relative affluence-dependent' intertemporal poverty measure $\tilde{P}_{R}$. (See Appendix A for details of the measures and parameters).

The two classes of measures have much in common. In particular, both account for the exacerbating effect of long periods of deprivation, and both allow prolonged periods of relative affluence to have a mitigating effect on subsequent periods of deprivation. They also have the same upper and lower bounds, and if their parameters $\alpha=\beta=0$ both collapse to Foster (2009)'s intertemporal poverty measure. ${ }^{9}$ The main difference between them is that with $P_{R}$, the mitigating effect of non-poor periods depends only on the length of time a household has been non-poor for, while with $\tilde{P}_{R}$, the extent of this mitigating effect can be increased if households are far above the poverty line when they are non-poor.

Dutta et al. (2013) justify their approach by arguing that periods of affluence allow people to accumulate valuable resources that help mitigate the deprivation experienced in subsequent poor spells. Implicit in their approach is that,

"... in the absence of income smoothing opportunities, the mitigating effect of affluent periods is transmitted through non-income dimensions such as assets, health, social networks, human capital and so on.” (p. 743).

\footnotetext{
${ }^{8}$ In principle, any of a wide range of static poverty indices from the literature can be used. The normalized poverty gap has some appealing properties, including sensitivity to the size of the shortfall and scale invariance. In the case of income, it also has a natural interpretation, when denormalized, as the minimum cost to society of removing a household from poverty.

${ }^{9}$ The upper and lower bounds are, respectively, $\frac{1}{T} \sum_{t=1}^{T} t^{\alpha}$, and 0 . It can be inferred from the dependence of the upper bound on $t$ that the measures can only consistently compare profiles of the same length.
} 
While they treat income-based poverty as their primitive, a similar justification certainly seems to hold for nutritional poverty, and indeed nutrition might be considered a dimension of poverty which Dutta et al. (2013)'s measures are particularly well suited to capturing. It is well known, for example, that people who have a possibility of falling into poverty often use their "body as a store of energy" during times of relative affluence by employing a "feast now fast later" strategy (Dercon and Hoddinott 2005, pp. 7-8). Moreover, intensification of nutritional poverty due to prolonged spells of low caloric intake is clearly a genuine phenomenon, with starvation and death a plausible outcome in extreme cases.

In our empirical analysis then, we estimate both $P_{R}$ and $\tilde{P}_{R}$ for two dimensions of household welfare: income and nutrition, to reveal the extent of intertemporal deprivations in these dimensions. Considering the substantial income growth and monetary poverty reduction in rural China over the period of analysis, we use the measures defined by $\tilde{P}_{R}$ to investigate the determinants of income and nutritional intertemporal deprivations, while using $P_{R}$ to check the robustness of results.

\subsection{Determinants of intertemporal poverty in multi-dimensions}

Having introduced our measures of household intertemporal deprivation, in income and nutrition, we proceed to investigating their determinants. It will first be convenient to denote the number of time periods in which a given household is below the poverty line in dimension $j \in\{1,2\}$ by $q_{j}$, where $j=1$ for income and $j=2$ for nutrition. Let $y_{j}=\mathbf{1}\left(q_{j}>0\right)$ so that binary variable $y_{1}=1\left(y_{2}=1\right)$ if and only if the household has suffered from income (nutritional) deprivation at least once over the period 2000-2004. ${ }^{10}$ Household intertemporal deprivation in one dimension (as captured by either of our measures), is a weighted average of per period measures. Thus, a non-zero intertemporal deprivation in a dimension is "observed" only for those who have experienced at least one period of deprivation in this dimension. In each dimension, those who have never been poor do not then have any intertemporal deprivation.

As Roope and Peters (2013) pointed out, it is possible that the phenomenon of having non-zero intertemporal poverty is a result of somewhat different factors from those which determine the overall extent of intertemporal poverty. Roope and Peters (2013) argued that this therefore suggests that estimates of the determinants of intertemporal poverty should be obtained by modelling the level of intertemporal poverty conditional on being intertemporally poor (equivalently, being poor in at least one time period). If this possibility is not accounted for, there is a risk of a type of "selection bias". As stressed by Roope and Peters (2013), this interpretation of 'selection' is somewhat different to that which the Heckman two-step procedure they advocate is most typically used to address - such as propensity to work in a labour market context. Clearly people do not self-select whether to be poor. Nonetheless, just as in the familiar labour market context, sample "selection" of including only non-zero observations of intertemporal poverty in a regression can be considered a form of omitted-variables bias. In Roope and Peters (2013)'s application of the Heckman two-step approach, the null hypothesis of no 'selection' bias can then be tested by the equivalent null hypothesis that the coefficient of the inverse Mills ratio is zero.

\footnotetext{
${ }^{10}$ Given the intertemporal nature of deprivation measures, the present study does not examine the dynamics of deprivation in each dimension or the impact of deprivation in one dimension on the magnitude of intertemporal deprivation in the other dimension. Rather, we use these outcome indicators of who are intertemporally deprived in each dimension to facilitate our selection models below.
} 
Multidimensionality further compounds the selection problem addressed in Roope and Peters (2013)'s unidimensional framework. ${ }^{11}$ We begin by making the strong assumption that income and nutritional deprivations, for a given household, are independent events. We construct a selection model to describe the household's observed intertemporal income deprivation $P_{1}$ (as estimated by $\tilde{P}_{R}$ and setting parameters $\alpha=\beta=\varphi=1, \gamma=2$ and $\delta=3.2$ ) as follows: ${ }^{12}$

$$
\begin{aligned}
& P_{1}=P_{1}^{*} \cdot \mathbf{1}\left(y_{1}>0\right) \\
& P_{1}^{*}=\mathbf{x}^{\prime} \beta_{1}+\bar{x}^{\prime} \beta_{2}+v_{1} \\
& y_{1}=\mathbf{1}\left(\mathbf{x}^{\prime} \theta_{1}+\bar{x}^{\prime} \theta_{2}+\mathbf{z}_{1}^{\prime} \theta_{3}+\varepsilon_{1}>0\right)
\end{aligned}
$$

Here, $\delta=3.2$ is calculated as below: in each wave, we calculate the ratio of the household income per adult equivalent, at the $75^{\text {th }}$ percentile of the income distribution, over the income deprivation line; then, we average these ratios across waves to obtain $\delta .{ }^{13}$ We consider those in the upper income quartile as being far above the deprivation line and this status is assumed to provide a greater mitigating impact on subsequent income deprivation than would a merely non-poor status; the greater mitigation is reflected by $\gamma=2$. In Eq. $1, P_{1}^{*}$ is a latent variable which captures the household's intertemporal income deprivation. It can take negative values, but a non-zero level of intertemporal deprivation is only observed $\left(P_{1}>0\right)$ for those who have at some time fallen below the income deprivation line; $\mathbf{x}^{\prime}=\left(x_{1}, \ldots, x_{k}\right)^{\prime}$ contains $k$ determinants of household income deprivation in the first wave; $\overline{\mathbf{x}}^{\prime}$ is a vector made up, for each household, of the intertemporal means of these $k$ variables, in order to control for at least some of the household specific unobserved time-invariant heterogeneity (Chamberlain, 1984, pp. 1250) that may underlie their intertemporal deprivation in each dimension; $\mathbf{z}_{1}^{\prime}$ contains the restriction, i.e., the excluded instrument, in order to enhance identification of the model. In particular, we use households' pre-determined income deprivation status in 1999 as the excluded instrument. It takes the value of one if the household's per capita equivalent net income in 1999 fell below a certain deprivation line and zero otherwise. It is closely related to households' subsequent per-period income poverty status, given the strong state dependence of poverty found by You (2016), but less so to Dutta et al. (2013)'s weighted average of income shortfall over the entire period of analysis - the correlation coefficient is 0.072 and statistically insignificant. ${ }^{14}$ Terms $\varepsilon_{1}$ and $v_{1}$ are the unobservables affecting the household's per-period income deprivation status, and the extent of its overall intertemporal income deprivation, respectively.

\footnotetext{
${ }^{11}$ This added difficulty is somewhat analogous to the added difficulty of identifying the poor in a multidimensional vis-à-vis uni-dimensional setting (see, for example, Alkire and Foster, 2011a, b). To continue the analogy, our approach could be interpreted as being analogous to identifying households as poor if they are deprived in at least one dimension. In two dimensions as important as income and nutrition this seems a reasonable approach.

${ }^{12}$ To keep the notation tractable, $P_{j}$ is used to denote the estimate of $\tilde{P}_{\mathrm{R}}$ in dimension $j \in\{1,2\}$.

${ }^{13}$ Using as high a threshold as this to define "absolute affluence" also helps mitigate the impact of measurement errors in income and nutrition on our results.

${ }^{14}$ Together with $\mathbf{z}_{2}$ in Eq. 2, weak instruments are sufficient to identify this system. See Roodman (2011) for technical details.
} 
Analogously, we also construct a selection model to describe the household's observed intertemporal nutritional deprivation $P_{2}$, also estimated by $\tilde{P}_{R}$ with the same parameter values as $P_{2}$, except for $\delta$, which is set at 1.05 , as follows:

$$
\begin{aligned}
& P_{2}=P_{2}^{*} \cdot \mathbf{1}\left(y_{2}>0\right) \\
& P_{2}^{*}=\mathbf{x}^{\prime} \beta_{1}+\overline{\mathbf{x}}^{\prime} \beta_{2}+v_{2} \\
& y_{2}=\mathbf{1}\left(\mathbf{x}^{\prime} \theta_{1}+\overline{\mathbf{x}}^{\prime} \theta_{2}+\mathbf{z}_{2}^{\prime} \theta_{3}+\varepsilon_{2}>0\right)
\end{aligned}
$$

Here, $\delta=1.05$ is calculated in a similar way as in the income dimension: in each wave, we calculate the ratio of the household nutrient intake per adult equivalent at the $75^{\text {th }}$ percentile of the nutrition distribution, over the nutritional deprivation line; then, we average these ratios across all waves to obtain $\delta$. We consider those in the upper nutrient quartile as being far above the nutrition deprivation line. Analogously to above, this status is assumed to provide a greater mitigating impact on subsequent nutritional deprivation than would a merely non-poor status; the enhanced mitigation is reflected by $\gamma=2$. In Eq. 2, $\mathbf{x}_{1}^{\prime}$ and $\overline{\mathbf{x}}^{\prime}$ are defined as before; the restrictions in the selection equation $\left(\mathbf{z}_{2}^{\prime}\right)$ are various food prices in the first wave in accordance with $\mathbf{x}_{1}^{\prime}$ and $\overline{\mathbf{x}}^{\prime}$, as these are closely related to households' perperiod nutritional intake, but less so to Dutta et al. (2013)'s weighted averages of nutrition shortfall over the entire period of analysis. ${ }^{15}$

The unobservables in the selection and outcome equations in one dimension are assumed to jointly affect both household per-period deprivation status $y_{j}$ through $\mathrm{y}_{j}^{*}$ and the extent of intertemporal deprivation over the entire period $P_{j}$. The two error terms then follow a binormal distribution for deprivations in two dimensions, that is $\left(v_{j}, \varepsilon_{j}\right) \sim N I D\left(0, \Sigma_{k}\right)$ where $j=\{1,2\}$ indicates the dimension (income or nutrition) and the variance-covariance matrix is given by $\boldsymbol{\Sigma}_{j}=\left[\begin{array}{cc}\sigma_{v_{j}}^{2} & \rho_{v_{j} \varepsilon_{j}} \sigma_{v_{j} \varepsilon_{j}} \\ \rho_{v_{j} \varepsilon_{j}} \sigma_{v_{j} \varepsilon_{j}} & 1\end{array}\right]$, where $\rho_{\varepsilon_{j} v_{j}} \neq 0$ to reflect interrelated $y_{j}$ and $P_{j}^{*}$ for the same household $i$ and $\sigma_{\varepsilon_{j}}^{2}=1$ to facilitate normalisation. Based on this, we use two approaches to estimate (1) and (2).

First, we encounter "selection" in our measures of "intertemporal poverty" as discussed in Section 2.1. That is, in any single dimension, a household is only "selected" in the sense of being observed as having a non-zero level of intertemporal poverty if it is below the poverty line in at least one time period. Applying the Heckman (1979) two-step procedures, to Eqs. 1 and 2 separately, yields consistent parameter estimates $\hat{\beta}$ and $\hat{\theta}$. The first step is to insert the inverse Mills' ratios, derived from the selection equations, $\lambda_{j}=\frac{\phi\left[-\left(\mathbf{x}^{\prime} \theta_{1}+\overline{\mathbf{x}}^{\prime} \theta_{2}+\mathbf{z}_{j}^{\prime} \theta_{3}\right)\right]}{1-\Phi\left[-\left(\mathbf{x}^{\prime} \theta_{1}+\overline{\mathbf{x}}^{\prime} \theta_{2}+\mathbf{z}_{j}^{\prime} \theta_{3}\right)\right]}$, where $j=1$ for income and $j=2$ for nutrition, as additional regressors in the two respective outcome equations. $\phi(\cdot)$ and $\Phi(\cdot)$ denote the standard and cumulative normal density functions, in turn. The augmented outcome equations are then estimated by OLS in the second step.

A conventional two-step method like Heckman (1979) relies less on the functional form, and so is more robust than other estimation strategies such as maximum likelihood (ML) estimation. Nevertheless, the two-step estimators are less efficient than the ML ones. Given

\footnotetext{
${ }^{15}$ The food items include grain, oil, vegetables, fruit, pork, beef, lamb, poultry, egg, alcohol, milk, and dairy products. They are also components in our calculations of households' nutrient intake. Their prices are calculated by the expenditure (in yuan) the household paid for this variety of food over the amount (in $\mathrm{kg}$ ) it purchased. The monetary values of prices are translated into real terms by the spatial price index.
} 
this, we also implement partial ML estimation and calculate the likelihood ratio statistics for the models. The likelihood function for Eqs. 1 and 2 can be written as:

$$
\begin{aligned}
& L_{j}=\prod_{y_{j}=0} \operatorname{Pr}\left(y_{j}=0 \mid \mathbf{z}_{j}, \mathbf{x}, \overline{\mathbf{x}}\right) \times \prod_{\substack{P_{j}>0 \\
y_{j}=1}} \operatorname{Pr}\left(y_{j}=1 \mid \mathbf{z}_{j}, \mathbf{x}, \overline{\mathbf{x}}\right) \operatorname{Pr}\left(P_{i j}=P_{i j}^{*} \mid \mathbf{z}_{j}, \mathbf{x}, \overline{\mathbf{x}}\right) \\
& =\prod_{i=1}^{N}\left\{\begin{array}{l}
{\left[\begin{array}{l}
\left.1-\Phi\left(\mathbf{x}^{\prime} \theta_{1}+\overline{\mathbf{x}}^{\prime} \theta_{2}+\mathbf{z}_{j}^{\prime} \theta_{3}\right)\right]^{\left(1-y_{i j}\right)} \\
\times\left[\Phi\left(\mathbf{x}^{\prime} \theta_{1}+\overline{\mathbf{x}}^{\prime} \theta_{2}+\mathbf{z}_{j}^{\prime} \theta_{3}\right) h_{j}\left(P_{j} \mid \mathbf{z}_{j}, \mathbf{x}, \overline{\mathbf{x}}, \sigma_{\varepsilon_{j} v_{j}}, \rho_{\varepsilon_{j} v_{j}}\right)\right]^{y_{i j}}
\end{array}\right\}}
\end{array}\right.
\end{aligned}
$$

where $j=\{1,2\}$ indicates income or nutritional deprivation, and $h_{j}\left(P_{j} \mid \mathbf{z}_{j}, \mathbf{x}, \overline{\mathbf{x}}, \sigma_{\varepsilon_{\mathbf{j}} v_{\mathbf{j}}}, \rho_{\varepsilon_{\mathbf{j}} v_{\mathbf{j}}}\right)$ is the conditional normal density function for the $j$ th outcome equation. The log-likelihood to be maximised takes the following expression under the joint bivariate normal distribution:

$$
\begin{aligned}
\ell_{j}= & \sum_{i=1}^{N}\left(1-y_{i j}\right) \ln \left[1-\Phi\left(\mathbf{x}^{\prime} \theta_{1}+\overline{\mathbf{x}}^{\prime} \theta_{2}+\mathbf{z}_{j}^{\prime} \theta_{3}\right)\right] \\
& +\sum_{i=1}^{N} y_{i j} \ln \Phi\left[\frac{\left(\mathbf{x}^{\prime} \theta_{\mathbf{1}}+\overline{\mathbf{x}}^{\prime} \theta_{\mathbf{2}}+\mathbf{z}_{\mathbf{j}}^{\prime} \theta_{\mathbf{3}}\right)+\left(\rho_{v_{j} \varepsilon_{j}} \sigma_{v_{j} \varepsilon_{j}} / \sigma_{v_{j}}^{2}\right)\left(p_{i j}-\mathbf{x}^{\prime} \beta_{1}-\overline{\mathbf{x}}^{\prime} \beta_{2}\right)}{\sqrt{1-\rho_{v_{j} \varepsilon_{j}}^{2} \sigma_{v_{j} \varepsilon_{j}}^{2} / \sigma_{v_{j}}^{2}}}\right] \\
& +\sum_{i=1}^{N} y_{i j} \ln \phi\left(\frac{P_{i j}-\mathbf{x}^{\prime} \beta_{\mathbf{1}}-\overline{\mathbf{x}}^{\prime} \beta_{\mathbf{2}}}{\sigma_{v_{j}}}\right)-\sum_{i=1}^{N} y_{i j} \ln \sigma_{v_{j}}
\end{aligned}
$$

Second, it is worth noting the household's inter-dependent deprivations in different dimensions. So far we have treated income and nutritional dimensions independently. A household could, however, be either just deprived in one of these dimensions during the period of analysis, or could endure both forms of deprivation during the $T$ periods (simultaneously or sequentially). In other words, for the same household, the unobservables that determine its multi-dimensional deprivation incidences, and the extent of deprivation in different dimensions, may well be correlated. For example, some of households' unobserved traits may simultaneously determine different aspects of their livelihood, e.g., low capabilities, cognitive skills, and personal preferences. The jointly distributed disturbances can also reflect some institutional or geographical factors that are not collected in our data but jointly determine different dimensions of wellbeing, e.g., low quality of governance, severe natural environment (which might be particularly the case for Gansu and Inner Mongolia as many areas are in the Gobi desert). We take these into account and model households' multi-dimensional intertemporal deprivations by the system containing, simultaneously, Eqs. 1 and 2, while the unobserved components for the same household $i,(\boldsymbol{\varepsilon}, \boldsymbol{v})^{\prime}=\left(\varepsilon_{1}, \varepsilon_{2}, v_{1}, v_{2}\right)^{\prime}$, are not independent, but jointly normally distributed across dimensions as $(\boldsymbol{\varepsilon}, \boldsymbol{v}) \mid \mathbf{x}, \overline{\mathbf{x}}, \mathbf{z} \sim N I D(0, \boldsymbol{\Sigma})$. The variance-covariance matrix $\boldsymbol{\Sigma}$ consists of the following elements:

$$
\boldsymbol{\Sigma}=\left[\begin{array}{cccc}
1 & \sigma_{\varepsilon_{1} \varepsilon_{2}} & \sigma_{\varepsilon_{1} v_{1}} & \sigma_{\varepsilon_{1} v_{2}} \\
\sigma_{\varepsilon_{1} \varepsilon_{2}} & 1 & \sigma_{\varepsilon_{2} v_{1}} & \sigma_{\varepsilon_{2} v_{2}} \\
\sigma_{\varepsilon_{1} v_{1}} & \sigma_{\varepsilon_{2} v_{1}} & 1 & \sigma_{v_{1} v_{2}} \\
\sigma_{\varepsilon_{1} v_{2}} & \sigma_{\varepsilon_{2} v_{2}} & \sigma_{v_{1} v_{2}} & 1
\end{array}\right]
$$


It has unit diagonal entries in order to normalise the scale for the equations in Eqs. 1 and 2. In other words, the correlation coefficients between the unobservables reduce to, for example, $\rho_{\varepsilon_{1} \varepsilon_{2}}=\operatorname{cov}\left(\varepsilon_{1}, \varepsilon_{2} \mid \mathbf{x}, \overline{\mathbf{x}}\right)=\sigma_{\varepsilon_{1} \varepsilon_{2}} \neq 0$.

This structure of $\boldsymbol{\Sigma}$ essentially transforms the model to a two-stage self-selection process with two selection criteria in the first stage and two outcomes in the second stage. The full sample therefore consists of four categories according to households' observed experiences in income and nutritional deprivations. These, and the corresponding probabilities, are:

(i) Always non-poor in both dimensions: $\operatorname{Pr}\left(y_{1}=0, y_{2}=0 \mid \mathbf{z}_{1}, \mathbf{z}_{2}, \mathbf{x}, \overline{\mathbf{x}}\right)$;

(ii) Poor in income at least once, while never poor in nutrition: $\operatorname{Pr}\left(P_{1}=P_{1}^{*}, P_{2}=0 \mid y_{1}=1, y_{2}=0, \mathbf{x}, \overline{\mathbf{x}}\right) \cdot \operatorname{Pr}\left(y_{1}=1, y_{2}=0 \mid \mathbf{z}_{1}, \mathbf{z}_{2}, \mathbf{x}, \overline{\mathbf{x}}\right) ;$

(iii) Poor in nutrition at least once, while never poor in income: $\operatorname{Pr}\left(P_{1}=0, P_{2}=P_{2}^{*} \mid y_{1}=0, y_{2}=1, \mathbf{x}, \overline{\mathbf{x}}\right) \cdot \operatorname{Pr}\left(y_{1}=0, y_{2}=1 \mid \mathbf{z}_{1}, \mathbf{z}_{2}, \mathbf{x}, \overline{\mathbf{x}}\right) ;$

(iv) Poor in both income and nutritional dimensions at least once, while poverty spells of two dimensions do not necessarily take place at the same time: $\operatorname{Pr}\left(P_{1}=P_{1}^{*}, P_{2}=P_{2}^{*} \mid y_{1}=1, y_{2}=1, \mathbf{x}, \overline{\mathbf{x}}\right) \cdot \operatorname{Pr}\left(y_{1}=1, y_{2}=1 \mid \mathbf{z}_{1}, \mathbf{z}_{2}, \mathbf{x}, \overline{\mathbf{x}}\right)$.

The likelihood function of the system (1) and (2) is the product of the probabilities of all four cases:

$$
\begin{aligned}
L & =\prod_{\substack{y_{1}=0, y_{2}=0\\
}} \operatorname{Pr}\left(y_{1}=0, y_{2}=0 \mid \mathbf{z}_{1}, \mathbf{z}_{2}, \mathbf{x}, \overline{\mathbf{x}}\right) \\
& \times \prod_{\substack{P_{1}>0, P_{2}=0 \\
y_{1}=1, y_{2}=0}} \operatorname{Pr}\left(P_{1}=P_{1}^{*}, P_{2}=0 \mid y_{1}=1, y_{2}=0, \mathbf{x}, \overline{\mathbf{x}}\right) \operatorname{Pr}\left(y_{1}=1, y_{2}=0 \mid \mathbf{z}_{1}, \mathbf{z}_{2}, \mathbf{x}, \overline{\mathbf{x}}\right) \\
& \times \prod_{\substack{P_{1}=0, P_{2}>0 \\
y_{1}=0, y_{2}=1}} \operatorname{Pr}\left(P_{1}=0, P_{2}=P_{2}^{*} \mid y_{1}=0, y_{2}=1, \mathbf{x}, \overline{\mathbf{x}}\right) \operatorname{Pr}\left(y_{1}=0, y_{2}=1 \mid \mathbf{z}_{1}, \mathbf{z}_{2}, \mathbf{x}, \overline{\mathbf{x}}\right) \\
& \times \prod_{\substack{P_{1}>0, P_{2}>0 \\
y_{1}=1, y_{2}=1}} \operatorname{Pr}\left(P_{1}=P_{1}^{*}, P_{2}=P_{2}^{*} \mid y_{1}=1, y_{2}=1, \mathbf{x}, \overline{\mathbf{x}}\right) \operatorname{Pr}\left(y_{1}=1, y_{2}=1 \mid \mathbf{z}_{1}, \mathbf{z}_{2}, \mathbf{x}, \overline{\mathbf{x}}\right)(5)
\end{aligned}
$$

On the assumption of multivariate normality of the error terms, Eq. 5 can be expressed as:

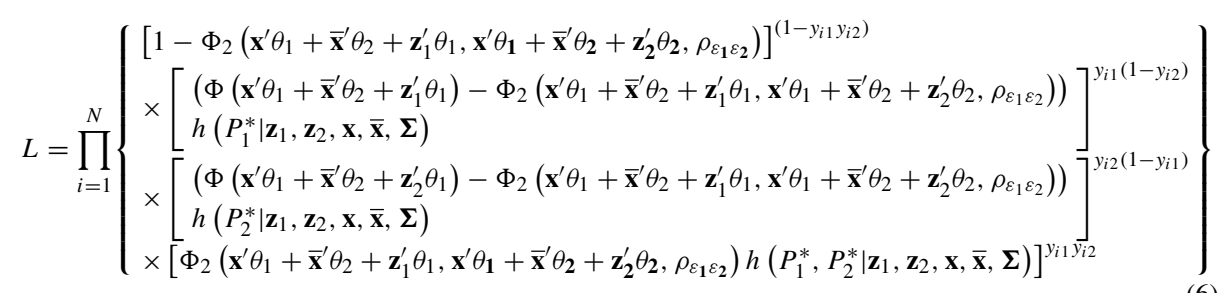

where $\Phi_{2}(\cdot)$ is the bivariate standard normal cumulative distribution function; $h(\cdot)$ denotes the conditional multivariate normal density function. The log transformation of Eq. 6 is evaluated by the maximum simulated likelihood (MSL) method using the GHK simulator to calculate the trivariate and four-variable normal integral and Halton draws (Roodman, 2011). 


\section{Data}

We employ a panel dataset in two western provinces of China, Gansu and Inner Mongolia, with 5 annual waves from 2000 to 2004. This incorporates data from individuals as well as surveys for their households and villages.

Our dataset was collected by the National Bureau of Statistics (NBS) local branches, covering 1,500 households in 150 villages from 15 counties. Of these, 700 households in 7 counties are in Gansu and the remaining 800 households are from 8 counties in Inner Mongolia. Gansu is one of the poorest provinces in China with its real per capita GDP ranking in the bottom 3 out of 31 provinces for two decades (1990-2010). ${ }^{16}$ By contrast, Inner Mongolia ranked in the middle (16-20) in the same period and was characterised by rich natural resources, typically coal mines, animal husbandry and related processing industries such as meat, dairy and cashmere. Enumerators regularly visited respondents throughout the year and income and consumption data were collected by the daily diary method. Therefore, the data should be expected to be more accurate than those relying on one-time interviews and memory and the non-response rate and attrition were negligible (Christiaensen et al. 2013). We use household equivalent units in our analysis. The modified OECD equivalence scale is used to adjust for household size and produce household monetary variables per equivalent adult. All monetary values are translated into real terms by using spatial price indices to obtain compatibility over time and between the two provinces. ${ }^{17}$

Income poverty reduction accelerated in the sample time period as a result of large-scale government-led investment projects and loans. The proportion of poor people in rural China declined from $10.46 \%$ in 2001 to $9.47 \%$ in 2004 under the US\$ 1-a-day poverty line (World Bank, 2009). Our dataset suggests a similar trend - as shown in Fig 1a, the total poverty incidence in our two sample provinces dropped from $12.5 \%$ in 2000 to $7.3 \%$ in 2004, under the same poverty line. Temporal 3.7-7.9 percentage point increases in total poverty rates can also be observed between 2000 and 2001 under three choices of income poverty lines. All increased poverty came from Inner Mongolia as suggested by the annual provincial poverty rates in Fig. 1a. Under the updated World Bank poverty line of US $\$ 1.25 /$ day, the poverty rate in Inner Mongolia in our data rose from 33.4\% in 2000 to $43.1 \%$ in 2001, which was possibly due to a grazing ban which was enforced between 15 March and 15 June in 2000 (Christiaensen et al. 2013). The poverty rate in Gansu declined consistently over the sample periods, while the magnitude was higher than that of Inner Mongolia in each wave except 2001. The slight increase in poverty rate from 2003 to 2004 in our data is consistent with the national poverty profile. According to the NBS, the first increase in the size of the poor population took place in 2003, when more than 80 million people returned to poverty due to natural disasters. ${ }^{18}$ In our data, the increased poverty rate in 2004 was driven largely by a 5.3 percentage points increase in Inner Mongolia. From January to June in 2004, drought swept Inner Mongolia and the rainfall dropped by $30-80 \%$ to the lowest level since $1951 .{ }^{19}$

As with poverty incidence, Fig. 2a shows that there was also an overall $37.5 \%$ decrease in the average income poverty gap (from $8 \%$ in 2000 to $5 \%$ in 2004) under the

\footnotetext{
${ }^{16}$ Authors' calculation based on data from China Statistical Yearbooks published annually by the NBS.

${ }^{17}$ See Table B.1 in Appendix for detailed definitions and descriptive statistics for all variables.

${ }^{18}$ The farming areas in China destroyed by natural disasters increased by $30.3 \%$ in 2003 according to the China Statistical Yearbook published annually by the NBS.

${ }^{19}$ Data come from the Report on the State of the Environment in China 2004 published by the Ministry of Environmental Protection.
} 


\section{(a) Income poverty rates}

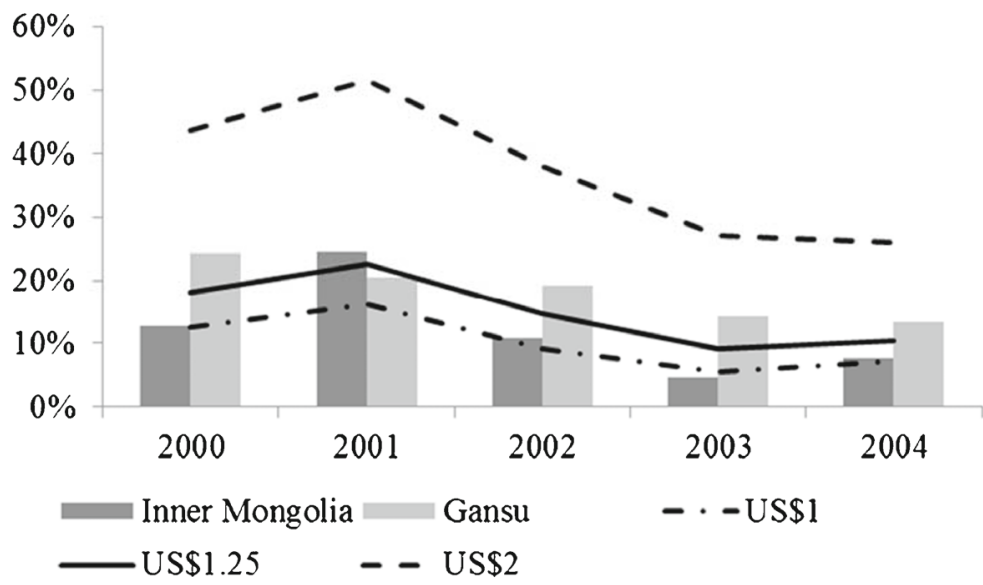

(b) Nutrition poverty rates

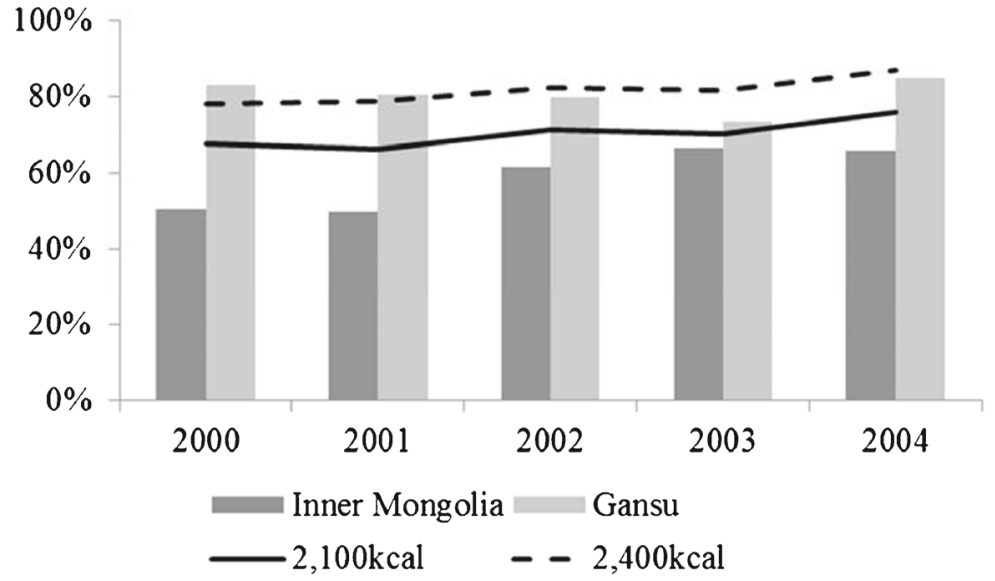

Fig. 1 Static poverty statistics. a Income poverty rates. b Nutrition poverty rates. The bars represent provincial poverty rates. They are calculated against the US\$1.25-a-day threshold in income dimension in (a) and the $2,100 \mathrm{kcal}$ per person per day in nutrition dimension in (b). The lines represent the average poverty rates across two provinces under different poverty thresholds. In particular, the solid lines represent poverty rates based on our preferred poverty thresholds - US $\$ 1.25 /$ day and 2,100 kcal - in estimation. The 2,100 kcal per person per day is a minimum threshold representing a bundle of 27 food items in 15 categories established in NBS (2000) from the mean consumption pattern of poor Chinese households with annual net income per capita less than the national poverty line of 800 yuan in 1998 prices. The 2,400 kcal per person per day is an upper threshold suggested by Park and Wang (2001). Similarly, China's Nutrition Association recommends $2,400 \mathrm{kcal} /$ day but reports $2,000 \mathrm{kcal}$ as a minimum caloric requirement. Source: Authors' calculation based on data in this paper

US\$1.25-a-day line. This is despite increases, mainly in Inner Mongolia, between 2000 and 2001, and after 2003, when poverty incidence also rose. The interesting observation from Fig. $2 \mathrm{a}$ is that the higher the income poverty line, the less the decrease in the poverty gap over time. This implies that those who escaped from severe poverty (say, the US\$1-a-day 
line) did not continue to improve their situation much further, but rather remained around the poverty line. This can be reaffirmed to some degree by the "extent of affluence" in Fig. 3: for the highest the poverty line, the gap between the household's observed income or nutrition and the poverty line increases least over time.

As the World Bank (2009), among others, has warned, successful reduction in income and consumption poverty does not necessarily synchronise with improvement in other dimensions of human well-being. We also examine nutritional poverty to recognise probable many-faceted hardship. Figure $1 \mathrm{~b}$ shows that incidence of nutritional poverty actually increased over the same period that incidence of income poverty declined. On average, $70 \%$ of sample households lived on less than 2,100 kcal per person per day. More people suffered

(a) Income poverty gap
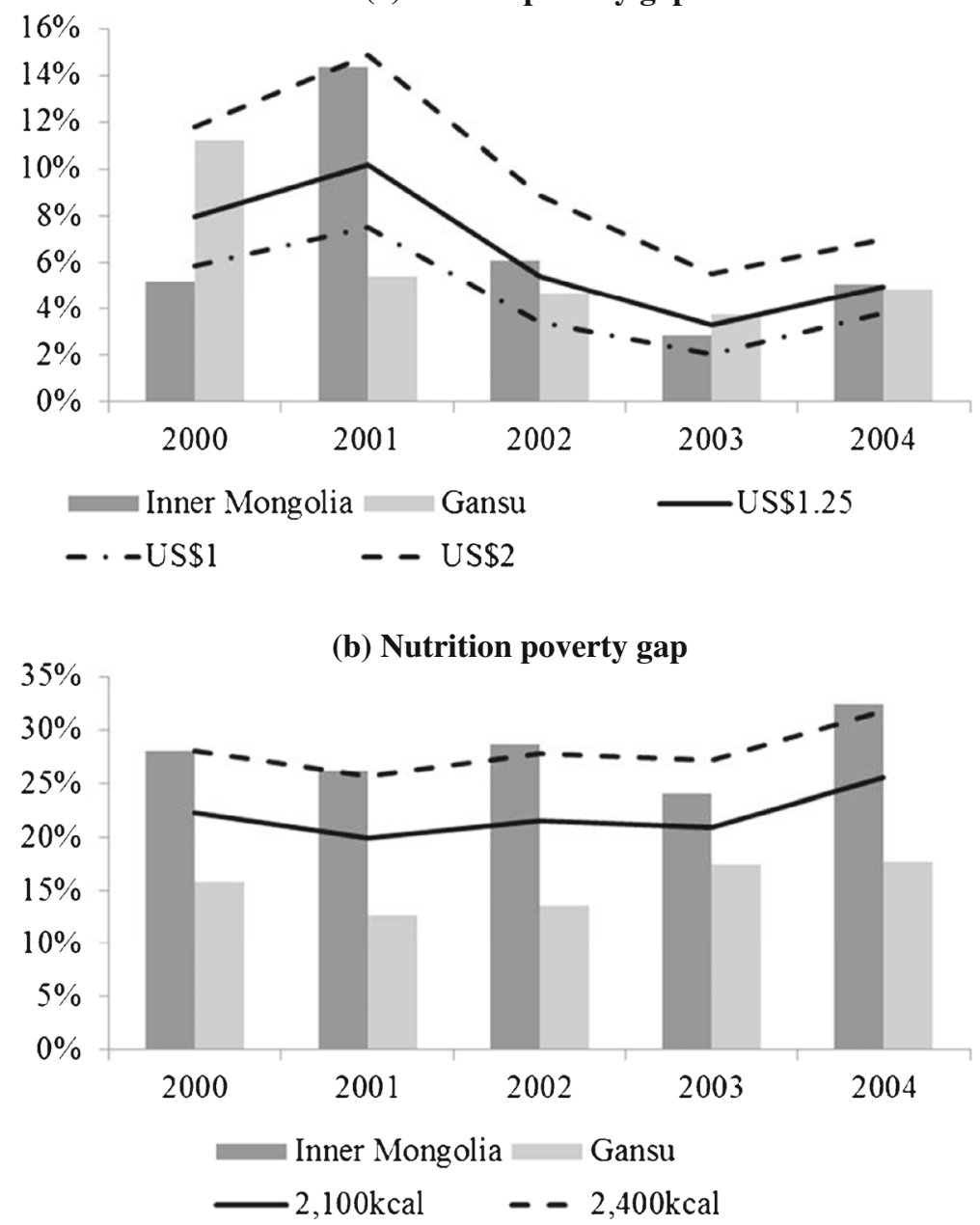

Fig. 2 Poverty gap. a Income poverty gap. b Nutrition poverty gap. The lines represent total poverty gap for two provinces under different poverty lines. The bars represent provincial poverty gap which is calculated under the US\$1.25-a-day and 2,100 kcal per person per day in income and nutrition dimensions, respectively. The sample size for the total poverty gap (indicated by lines) is 1,500 in two sample provinces. The sample sizes for Gansu and Inner Mongolia (indicated by bars) are 700 and 800 households, respectively 
from nutritional shortage than from income deprivation throughout the sample period, and the gap between the incidence rates of the two kinds of deprivation widened, as can be seen by comparing Fig. $1 \mathrm{a}$ and $\mathrm{b}^{20}$ The nutritional poverty rate increased by about 8 percentage points (12\% of proportional change) from 2000 to 2004, while household equivalent per capita net income grew by $31 \%$ concurrently. ${ }^{21}$ Cross-tabulating nutrition and income poverty status, we find that among households with insufficient nutrient intake, compared with the income poor, those earning higher income than the US\$1.25-a-day line spent more in production (including inputs in agricultural production and purchasing productive assets) and in living expenditure such as cloth, housing, transportation, education and gifts to relatives and friends, at $1-5 \%$ significance levels. In other words, in extremely poor regions, those suffering from nutrition poverty but not income poverty might trade off their nutrient consumption to safeguard their limited productive assets for higher income (which has been modelled theoretically by Zimmerman and Carter (2003), and empirically found in rural China by You, 2014), better living standards and to support education. The depth of nutritional poverty also increased. The average nutrition poverty gap, which is illustrated in Fig. 2 b, increased by $14.4 \%$ during 2000 to 2004 , under the $2,100 \mathrm{kcal}$ threshold, from $22.3 \%$ in 2000 to $25.5 \%$ to 2004 . This seems to have been driven largely by a further

\footnotetext{
${ }^{20}$ Note that our construction of household caloric intake is subject to substantial downside bias. For one thing, eating away from home was not taken into account. The dataset only has expenditure on eating away from home, e.g., in restaurants; caloric intake was not recorded. Indeed, household average annual expenditure on eating outside is more than 1.3 times larger for those whose nutrient intake was less than 2,100 kcal, than for those lying above this threshold, significant at the $1 \%$ level. This indicates that some nutrition poor could have been classified as non-poor if there were data on nutrient intake from eating away from home. Second, food consumption of those who temporarily out-migrated (i.e., "circular migration") might not be recorded given a diary method of data collection. Third, there might be measurement errors during the process of data collection. Over the period 1999-2004, households were required to keep records of their activities and officials of the provincial branches of the NBS regularly visited sample households throughout the year. There could be (cumulative) measurement errors during this process, especially given such a long time span (6 years). As a result of under-reported caloric intake, nutrient poverty statistics in Figures 1(b) and 2(b) might have been over-estimated. To estimate the extent of overestimation, we converted the US\$2 to equivalent food expenditure by multiplying the food shares in the income poverty line (67\%) used by the NBS for Gansu in 1999 (Park and Wang, 2001). This estimated food poverty line points to a poverty rate of $61.3 \%$ in 2000 . Comparing the nutrient poverty incidence (about $70 \%$ ) in Fig. 1b, the above measurement errors might exacerbate the nutrition poverty by $14 \%(\approx(70-61.3 \%) / 61.3 \%))$. We also calculated the average Engel's coefficient in rural Gansu over the sample period based on the China Statistical Yearbooks published by the NBS) and multiplied it $(0.46)$ by the US $\$ 2$ poverty line. Using this as the food threshold, the food poverty incidence becomes $28.4 \%$, equivalent to $146 \%$ of overestimation of our nutrient poverty incidence. Despite higher per-period nutrition poverty statistics, the increasing trend of nutrition poverty over time is consistent between our dataset and another large household panel dataset, the China Health and Nutrition Survey (CHNS, 1989-2009), which covers 9 provinces (but without Gansu or Inner Mongolia).

${ }^{21}$ The CHNS (1989-2009) also manifests little correlation (0.4) between income and nutrient intake (Shimokawa, 2013), and decreasing calorie intake (Zhao et al. 2013), even after controlling for reduced intensity of physical activities and shifts in food preferences (You et al. 2016). Similar phenomena have also been observed in India in 2004-2009 (Gaiha et al. 2014), Nicaragua in 2005-2007 and Nigeria (Ogundari and Abdulai, 2013). FAO (2013) argues that nutrition is weakly associated with income in countries or regions where food insecurity is more pervasive. You et al. (2016) find that income growth is associated with higher nutrient intake for Chinese urban, rather than rural, households, and that higher and more volatile food prices also retard improvement in nutrition, especially for those with limited income. Zhai et al. (2014) document changes in nutrient composition - shifting away from traditional foods with (low-fat and high-fibre) coarse grains to westernised ones, which are salty and high in carbohydrates, and in food behaviour, including a decrease in healthy cooking methods.
} 


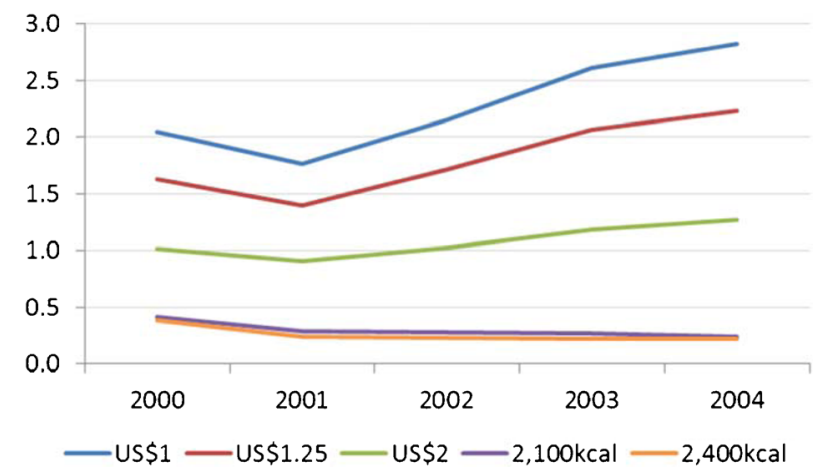

Note: The vertical axis measures the average ratio of the household's observed income (nutrient intake) per equivalent adult over different income (nutrition) poverty lines. This figure depicts the total relative affluence in these dimensions in our two sample provinces.

Fig. 3 Extent of affluence. The vertical axis measures the average ratio of the household's observed income (nutrient intake) per equivalent adult over different income (nutrition) poverty lines. This figure depicts the total relative affluence in these dimensions in our two sample provinces

increase in the already substantial depth of nutrition poverty in Inner Mongolia. Also alarmingly, the "extent of affluence" in Fig. 3 in the nutrition domain is relatively stable over time, with even a slightly decreasing trend. ${ }^{22}$

Over time, chronic and transient poverty have co-existed in rural China with the former being slightly more dominant than the latter (e.g., Jalan and Ravallion, 1998 for the 1980s; McCulloch and Calandrino, 2003 for the first half of the 1990s; Duclos et al. 2010 for the period 1986-2002; and Wan and Zhang, 2013 for two decades from 1985 to 2005). Our data are consistent with these findings. Refer to Appendix C for a detailed description.

\section{Estimation results and discussion}

\subsection{Household intertemporal deprivations}

The analyses henceforth, except where specified, are based on the deprivation thresholds of US $\$ 1.25 /$ day for income and 2,100 kcal for nutrition. Figures 4 and 5 draw the distributions of two kinds of intertemporal poverty measures $\left(P_{R}\right.$ and $\left.\tilde{P}_{R}\right)$ in two dimensions separately. Table 1 reports the mean of the full sample and of various subsamples.

Two observations can be drawn from Figs. 4 and 5. First, comparing income and nutrition dimensions, intertemporal income poverty is more right-skewed than intertemporal nutrition poverty. For example, when " $\alpha=\beta=\varphi=1$ ", the standard deviation of $\tilde{P}_{R}$ in the income dimension (0.169) is only one third of that of the nutrition dimension (0.499). The former is $45 \%$ of the latter if using $P_{R}$. These are predictable given the poverty dynamics and transition in our data - the more frequently the sample households move into and out of poverty (as described in Appendix C), the more heterogeneous their intertemporal poverty indices

\footnotetext{
${ }^{22}$ It should be borne in mind that the scope for very high levels of "affluence" in nutrition is considerably more limited than is the case for income, as there are physical limits to the number of calories people can eat.
} 
(a) Income

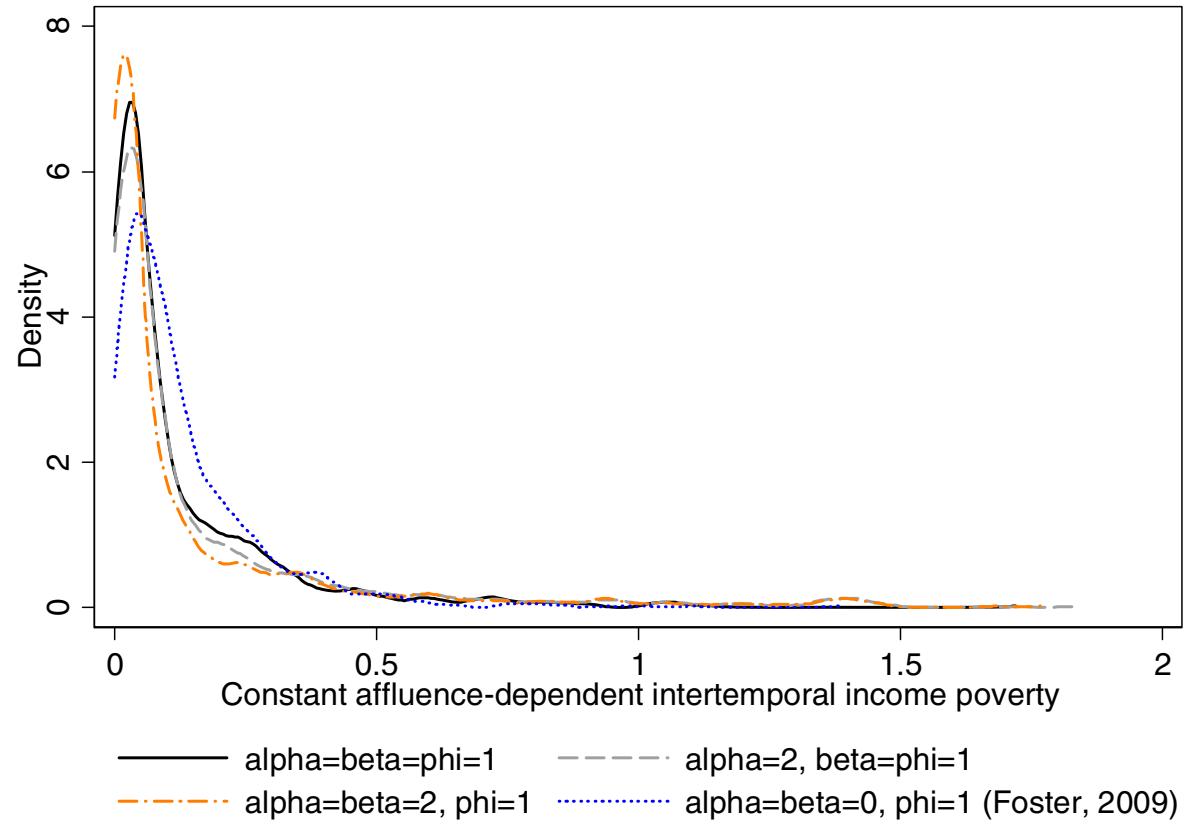

(b) Nutrition

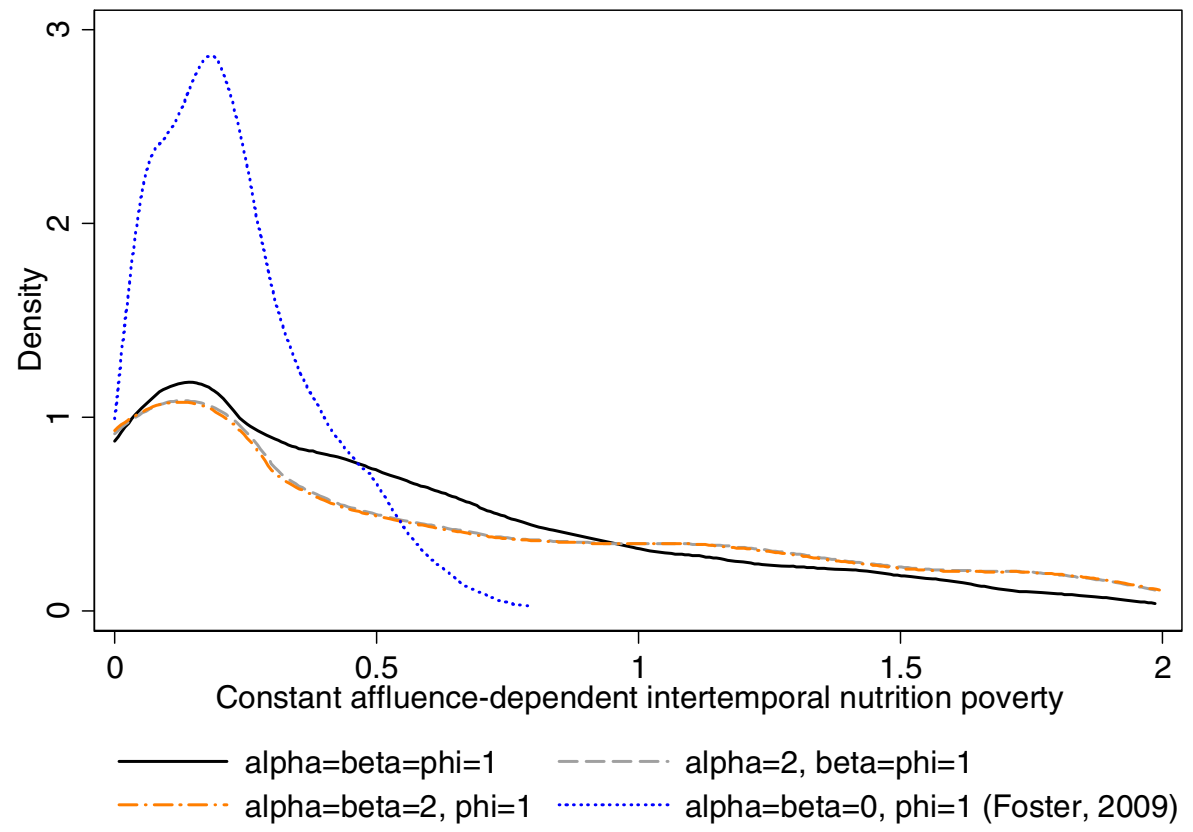

Fig. 4 Distribution of constant affluence-dependent intertemporal poverty. a Income. b Nutrition. Source: Authors' calculation based on the survey data in Gansu and Inner Mongolia 
(a) Income

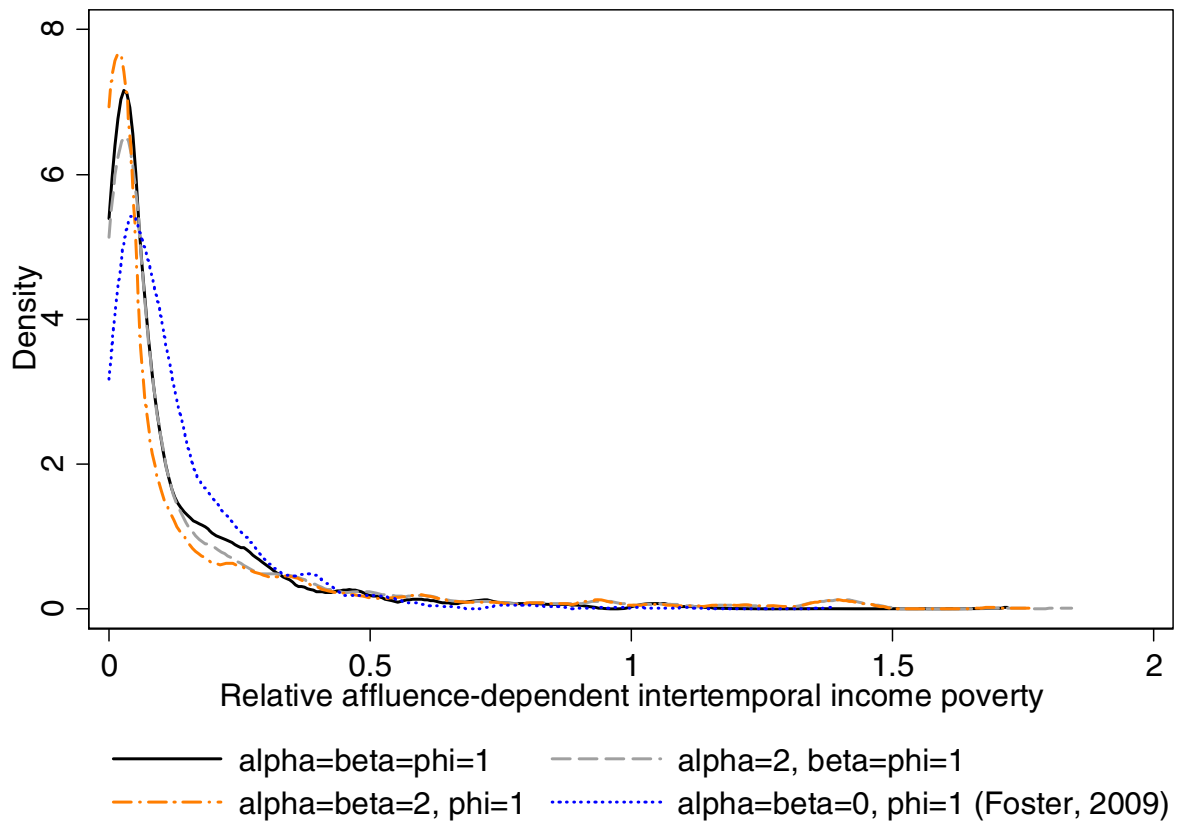

(b) Nutrition

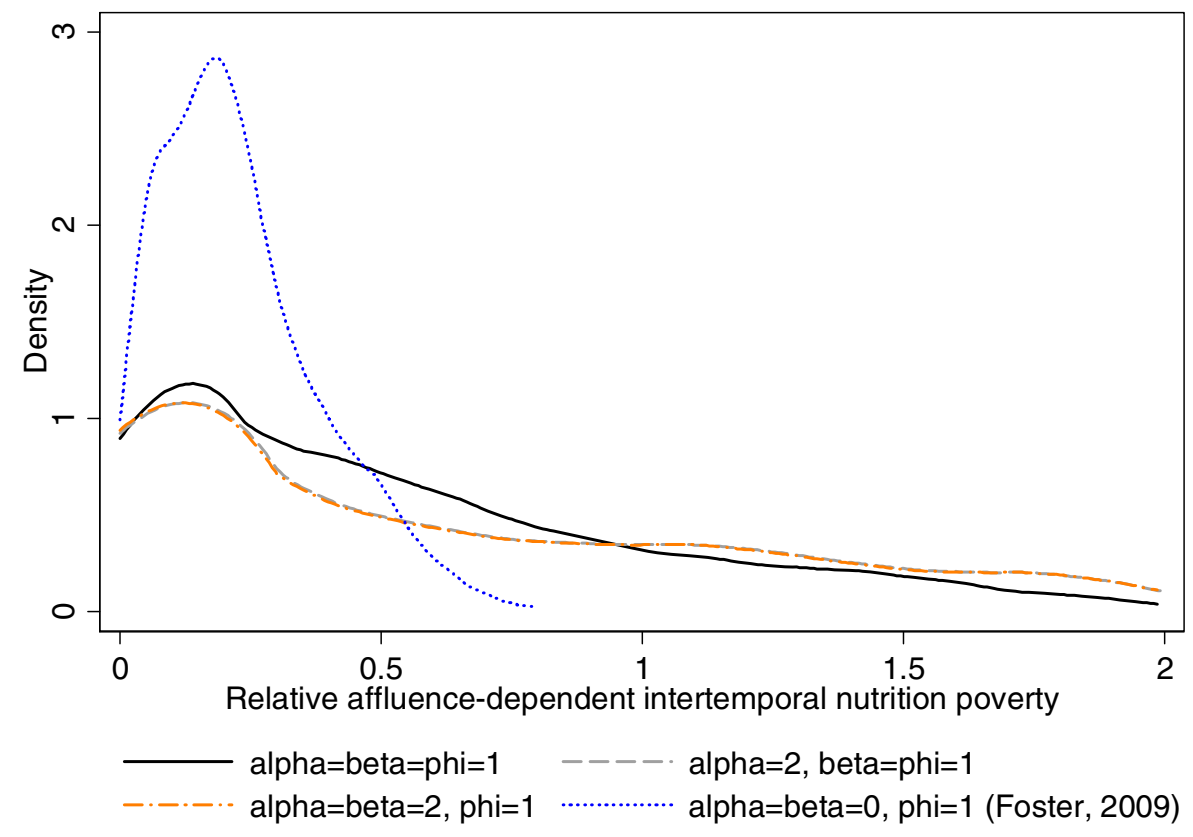

Fig. 5 Distribution of relative affluence-dependent intertemporal poverty. a Income. b Nutrition. Source: Authors' calculation based on the survey data in Gansu and Inner Mongolia 
when allowing for different degrees of intensification (of past poverty) and mitigation (of past affluence).

Second, between different measures controlled by three parameters $(\alpha, \beta$ and $\phi)$ within each dimension, stronger intensification ( $\alpha$ from zero to 2 ) makes the distribution flatter and extends the right tail (especially in the nutrition dimension), resulting in a higher average level of intertemporal poverty (as demonstrated by Column 1 of Table 1). Allowing for stronger mitigating impact of affluent spells, but with the same intensification, i.e., comparing the grey and orange lines ( $\beta$ from 1 to 2 ), makes little change to the distribution. This corresponds to Fig. 3 in Section 3 - affluent spells are not sufficiently "strong/large" to offset past hardship.

The average intertemporal income deprivation over the entire sample period is 0.064 , without accounting either for any intensification imposed by previous poor spells, or for any mitigating effects of previous affluent spells (i.e., Foster's (2009) indicator in Column 1 of Table 1).

To give an indication of the role that the actual levels of incomes during poor periods have in this estimate, Foster's (2009) measure would be 1.3 times larger (0.15) if we hypothesise the maximum poverty gap, which is one, for every poor episode, while keeping income or nutrition in non-poor periods as it is (which does not, in any case, affect Foster's (2009) measure). Nevertheless, if every household could enjoy sufficient affluence (i.e., assigning the $75^{\text {th }}$ percentile observed income (nutrition) level to every household in each of their non-poor spells or, in other words, setting $x_{t^{\prime}}=\delta z=3.2 z(\delta z=1.05 z)$ in every nonpoor spell), while experiencing the actual observed depth of deprivation in poor spells, their relative-constant intertemporal deprivation, according to $\tilde{P}_{R}(\mathbf{p})$ with $\alpha=\beta=\varphi=1$, $\gamma=2$ and $\delta=3.2$ would have dropped from 0.063 to 0.059 in the income dimension and from 0.525 to 0.520 in the nutrition dimension. The above exercise suggests that these "notso-poor" households not only confronted the risk of returning to deprivation, as they still remained close to the deprivation threshold, but also benefitted less from non-poor periods than those who had successfully managed to escape far from the deprivation threshold, at least according to $\tilde{P}_{R}(\mathbf{p})$. China has long focused on reducing poverty incidence and the number of the population living below certain lines, but the above analysis reveals an important role of extended and continuous support for those just escaping deprivation, if they are to have sustained welfare improvement, especially in regions where chronic and transient poverty co-exist.

We also calculate each intertemporal measure for selected sub-populations. ${ }^{23}$ Geographically, the poorer province, Gansu, experienced higher intertemporal deprivation than the wealthier one, Inner Mongolia, in all measures of the income dimension. Nevertheless, intertemporal nutritional deprivation is found to be much higher in Inner Mongolia than in Gansu (Columns 5-6 of Table 1), even affluent periods are allowed to have a mitigating effect. This could be driven primarily by a $19-49 \%$ larger nutritional poverty gap in Inner Mongolia than in Gansu throughout the sample period as shown in Fig. 2b, although the nutritional poverty incidence was actually lower in the former as shown in Fig. $1 b$.

According to the production activity to which the household allocates the most labour (days per year), we divide the full sample into agricultural, local non-agricultural and circular migrating households. Interestingly, those putting the most labour into local nonagricultural production were least poor in both income and nutrition, but relying on circular

\footnotetext{
${ }^{23}$ The division of samples does not consider gender, as only 7 out of 1,500 households were headed by females.
} 
Table 1 Intertemporal poverty profile

\begin{tabular}{|c|c|c|c|c|c|c|c|c|}
\hline \multirow[t]{2}{*}{ Group } & \multicolumn{2}{|c|}{ US\$1.25 } & \multicolumn{2}{|l|}{ US\$2 } & \multicolumn{2}{|c|}{$2,100 \mathrm{kcal}$} & \multicolumn{2}{|c|}{$2,400 \mathrm{kcal}$} \\
\hline & $\begin{array}{l}P_{R}(\mathbf{p}) \\
(1)\end{array}$ & $\begin{array}{l}\tilde{P}_{R}(\mathbf{p}) \\
(2)\end{array}$ & $\begin{array}{l}P_{R}(\mathbf{p}) \\
(3)\end{array}$ & $\begin{array}{l}\tilde{P}_{R}(\mathbf{p}) \\
(4)\end{array}$ & $\begin{array}{l}P_{R}(\mathbf{p}) \\
(5)\end{array}$ & $\begin{array}{l}\tilde{P}_{R}(\mathbf{p}) \\
(6)\end{array}$ & $\begin{array}{l}P_{R}(\mathbf{p}) \\
(7)\end{array}$ & $\begin{array}{l}\tilde{P}_{R}(\mathbf{p}) \\
(8)\end{array}$ \\
\hline \multicolumn{9}{|l|}{$\alpha=\beta=\varphi=1$} \\
\hline Full sample & 0.064 & 0.063 & 0.223 & 0.220 & 0.524 & 0.521 & 0.744 & 0.740 \\
\hline \multicolumn{9}{|l|}{ Geography } \\
\hline Gansu & 0.068 & 0.067 & 0.314 & 0.313 & 0.322 & 0.318 & 0.513 & 1.658 \\
\hline Inner Mongolia & 0.061 & 0.058 & 0.143 & 0.139 & 0.701 & 0.698 & 0.946 & 3.291 \\
\hline \multicolumn{9}{|l|}{ Labour allocation } \\
\hline Agriculture & 0.070 & 0.069 & 0.243 & 0.240 & 0.527 & 0.513 & 0.746 & 0.731 \\
\hline Local non-agriculture & 0.023 & 0.040 & 0.120 & 0.158 & 0.506 & 0.544 & 0.743 & 0.772 \\
\hline Circular migration & 0.117 & 0.090 & 0.221 & 0.247 & 0.532 & 0.510 & 0.697 & 0.715 \\
\hline \multicolumn{9}{|l|}{ Ethnicity } \\
\hline Han & 0.120 & 0.121 & 0.249 & 0.251 & 0.768 & 0.759 & 0.942 & 0.930 \\
\hline Minorities & 0.059 & 0.058 & 0.220 & 0.218 & 0.503 & 0.500 & 0.727 & 0.724 \\
\hline \multicolumn{9}{|l|}{$\alpha=2, \beta=\varphi=1$} \\
\hline Full sample & 0.119 & 0.117 & 0.574 & 0.572 & 1.707 & 1.704 & 2.538 & 2.534 \\
\hline \multicolumn{9}{|l|}{ Geography } \\
\hline Gansu & 0.129 & 0.129 & 0.876 & 0.876 & 0.974 & 0.970 & 1.669 & 1.664 \\
\hline Inner Mongolia & 0.110 & 0.108 & 0.309 & 0.306 & 2.349 & 2.346 & 3.298 & 3.295 \\
\hline \multicolumn{9}{|l|}{ Labour allocation } \\
\hline Agriculture & 0.132 & 0.131 & 0.631 & 0.627 & 1.712 & 1.673 & 2.532 & 2.493 \\
\hline Local non-agriculture & 0.038 & 0.069 & 0.295 & 0.399 & 1.664 & 1.796 & 2.591 & 2.666 \\
\hline Circular migration & 0.207 & 0.179 & 0.479 & 0.602 & 1.811 & 1.704 & 2.397 & 2.471 \\
\hline \multicolumn{9}{|l|}{ Ethnicity } \\
\hline Han & 0.279 & 0.283 & 0.696 & 0.703 & 2.451 & 2.425 & 3.095 & 3.057 \\
\hline Minorities & 0.106 & 0.103 & 0.564 & 0.561 & 1.644 & 1.641 & 2.490 & 2.489 \\
\hline \multicolumn{9}{|l|}{$\alpha=\beta=2, \varphi=1$} \\
\hline Full sample & 0.111 & 0.110 & 0.564 & 0.563 & 1.701 & 1.700 & 2.532 & 2.529 \\
\hline \multicolumn{9}{|l|}{ Geography } \\
\hline Gansu & 0.124 & 0.124 & 0.868 & 0.868 & 0.967 & 0.964 & 1.661 & 1.658 \\
\hline Inner Mongolia & 0.100 & 0.099 & 0.298 & 0.296 & 2.343 & 2.340 & 3.293 & 3.291 \\
\hline \multicolumn{9}{|l|}{ Labour allocation } \\
\hline Agriculture & 0.123 & 0.123 & 0.621 & 0.617 & 1.706 & 1.668 & 2.526 & 2.488 \\
\hline Local non-agriculture & 0.034 & 0.064 & 0.288 & 0.391 & 1.657 & 1.791 & 2.585 & 2.662 \\
\hline Circular migration & 0.200 & 0.170 & 0.469 & 0.591 & 1.806 & 1.698 & 2.390 & 2.465 \\
\hline \multicolumn{9}{|l|}{ Ethnicity } \\
\hline Han & 0.269 & 0.274 & 0.686 & 0.694 & 2.447 & 2.420 & 3.090 & 3.053 \\
\hline Minorities & 0.098 & 0.096 & 0.554 & 0.551 & 1.637 & 1.636 & 2.484 & 2.483 \\
\hline \multicolumn{9}{|c|}{$\alpha=\beta=0, \varphi=1$ (Foster, 2009) } \\
\hline Full sample & 0.064 & & 0.137 & & 0.221 & & 0.288 & \\
\hline \multicolumn{9}{|l|}{ Geography } \\
\hline Gansu & 0.060 & & 0.168 & & 0.154 & & 0.218 & \\
\hline Inner Mongolia & 0.067 & & 0.111 & & 0.279 & & 0.350 & \\
\hline
\end{tabular}


Table 1 (continued)

\begin{tabular}{|c|c|c|c|c|c|c|c|c|}
\hline \multirow[t]{2}{*}{ Group } & \multicolumn{2}{|c|}{ US $\$ 1.25$} & \multicolumn{2}{|l|}{ US\$2 } & \multicolumn{2}{|c|}{$2,100 \mathrm{kcal}$} & \multicolumn{2}{|c|}{$2,400 \mathrm{kcal}$} \\
\hline & $\begin{array}{l}P_{R}(\mathbf{p}) \\
(1)\end{array}$ & $\begin{array}{l}\tilde{P}_{R}(\mathbf{p}) \\
(2)\end{array}$ & $\begin{array}{l}P_{R}(\mathbf{p}) \\
(3)\end{array}$ & $\begin{array}{l}\tilde{P}_{R}(\mathbf{p}) \\
(4)\end{array}$ & $\begin{array}{l}P_{R}(\mathbf{p}) \\
(5)\end{array}$ & $\begin{array}{l}\tilde{P}_{R}(\mathbf{p}) \\
(6)\end{array}$ & $\begin{array}{l}P_{R}(\mathbf{p}) \\
(7)\end{array}$ & $\begin{array}{l}\tilde{P}_{R}(\mathbf{p}) \\
(8)\end{array}$ \\
\hline \multicolumn{9}{|l|}{ Labour allocation } \\
\hline Agriculture & 0.070 & & 0.148 & & 0.222 & & 0.290 & \\
\hline Local non-agriculture & 0.027 & & 0.080 & & 0.213 & & 0.282 & \\
\hline Circular migration & 0.096 & & 0.155 & & 0.210 & & 0.272 & \\
\hline \multicolumn{9}{|l|}{ Ethnicity } \\
\hline Han & 0.089 & & 0.144 & & 0.325 & & 0.383 & \\
\hline Minorities & 0.061 & & 0.137 & & 0.212 & & 0.280 & \\
\hline
\end{tabular}

Note: The sample size for the full sample and each category is 1,500. For the relative-affluent measures $\left(\tilde{P}_{R}(\mathbf{p})\right)$ in Eq. 2 , we set $\delta=3.2$ for income and 1.05 for nutrition

migration made households worse-off intertemporally, especially when referring to relatively low income and nutrition poverty lines (e.g., Columns 1,2 and 5 of Table 1). We will return to this by discussing the roles of different labour productivity in Section 4.2. Ethnic identity appears to be an additional correlate of intertemporal poverty. The household was substantially less intertemporally poor if at least one family member belonged to an ethnic minority. This is consistent with the exploratory data analysis in Section 3 that the ethnically autonomous province, Inner Mongolia, was richer than Gansu in every wave. Together with higher average intertemporal nutrition deprivation in Inner Mongolia than in Gansu, we conjecture that the Han people in Inner Mongolia might struggle with the toughest nutritional shortage in the study population.

All discussions so far also hold broadly for higher deprivation thresholds (Columns 3-4 and 7-8 of Table 1). As expected, the same intertemporal deprivation measure is always higher under the higher threshold than that under the lower one.

\subsection{The roles of agriculture and household material well-being in determining intertemporal poverty}

Table 2 summarises the two-step estimation results of Eqs. 1 and 2, which attempt to identify the determinants of household multi-dimensional intertemporal deprivations. The estimated coefficient of the inverse Mills' ratio is broadly statistically significant in both income and nutrition models, implying the existence of endogeneity and lending some justification to our choice of estimation approach, as this estimator essentially captures the correlation between the probability of being poor and the extent of intertemporal deprivation, i.e., $\hat{\rho}_{v_{j} \varepsilon_{j}} \hat{\sigma}_{v_{j}}^{2}$, with $j=\{1,2\}$ denoting the income or nutritional dimension. ${ }^{24}$ Re-estimating

\footnotetext{
${ }^{24}$ That $\hat{\lambda}$ is significantly positive in income regressions and negative in nutrition regressions means that more able households would earn more income but consume fewer calories. This is consistent with the aforementioned observations of higher income but lower nutrient intake in Section 3. Relatively large magnitude of highly significant $\hat{\lambda}$ in the nutrition dimension might signal misspecification of the model. To test for nonlinearity in $\hat{\lambda}$, we scatter-plotted $\hat{\lambda}$ (in Columns 7 and 8 of Table 2 , respectively) against predicted values of the selection variable in the nutrition dimension. Both suggest clear nonlinearity, indicating satisfactory identification under the "instruments" - unit prices of various food items in the first wave. We also used unit
} 


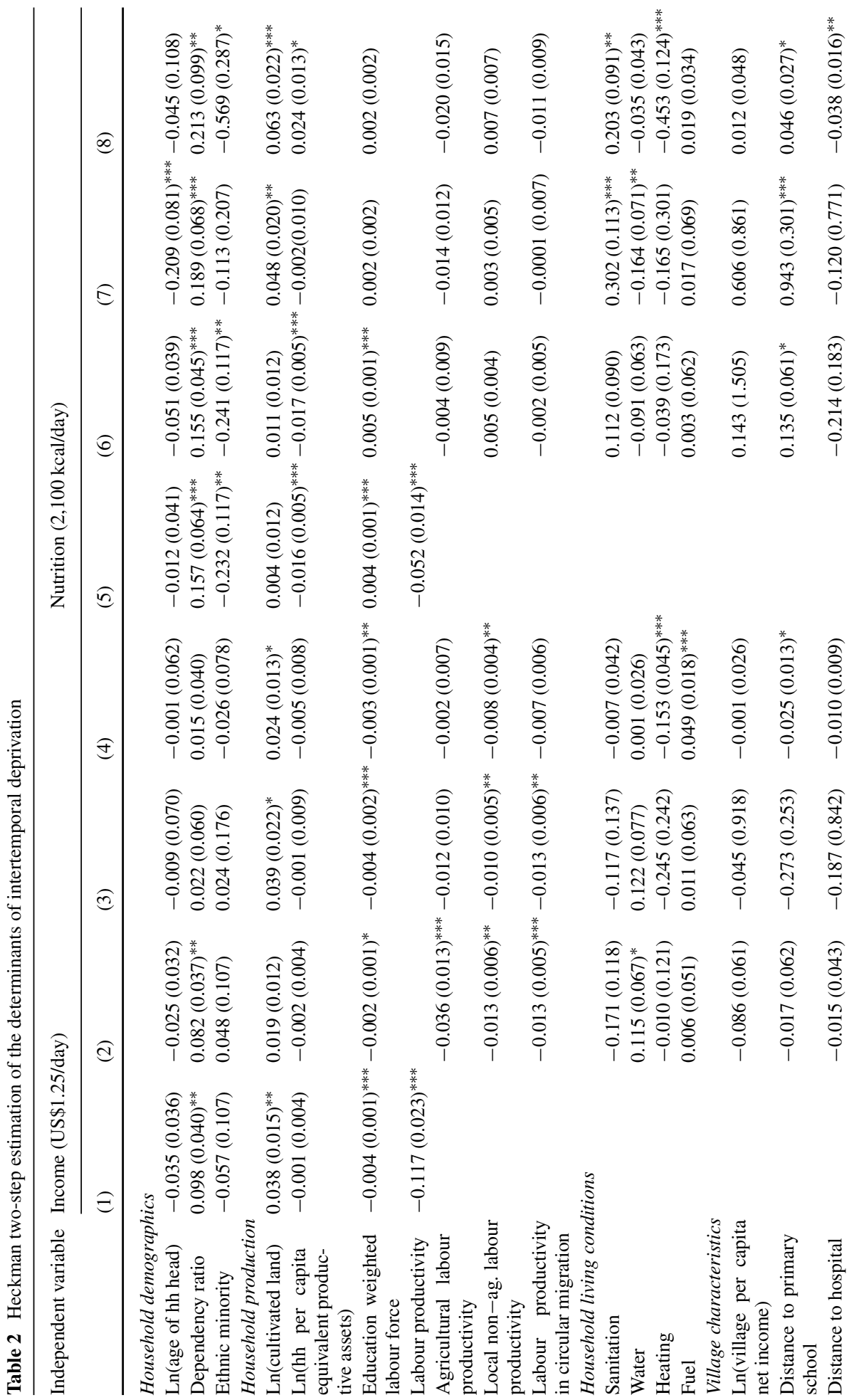




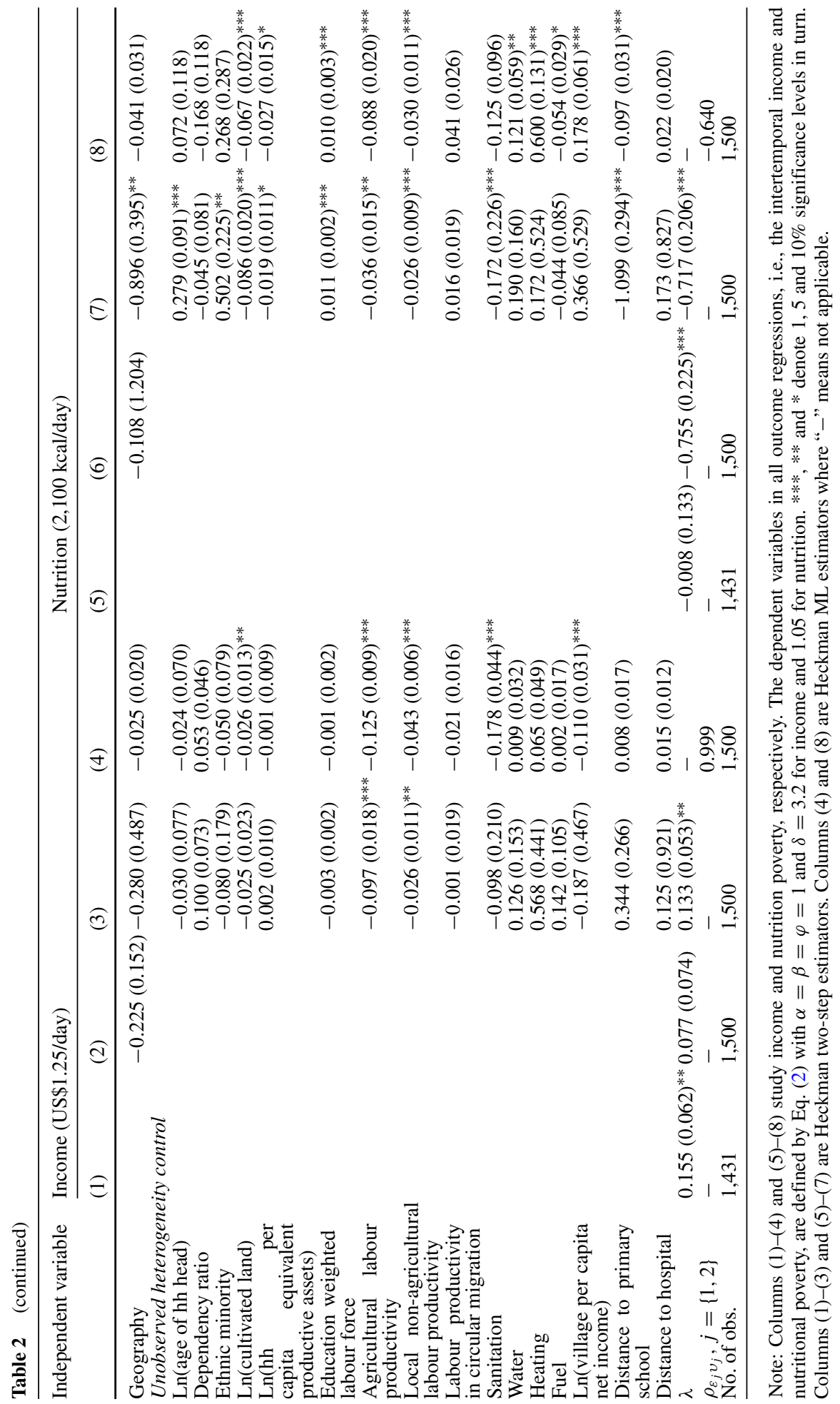


Columns (3) and (7) of Table 2 by ML (3) yields broadly similar results shown in Columns (4) and (8), but with smaller standard errors - as expected since ML is more efficient than two-step estimation. The correlation coefficient between the errors in selection and outcome regressions $\left(\hat{\rho}_{\varepsilon_{j}} v_{j}\right.$ with $\left.j=\{1,2\}\right)$ is positive in income (0.99) and negative in nutrition $(-0.64)$ dimensions, both significantly different from zero with the $F$-statistics being 6.61 $(p$-value $=0.01)$ for income and $24.3(p$-value $=0.00)$ for nutrition. This also corroborates the existence and direction of endogeneity within each poverty dimension identified by Heckman two-step estimators. ${ }^{25}$

Table 3 reports estimation results of Eq. 6, further correcting for simultaneity between income and nutritional deprivation. The bottom panel of Table 3 reports cross-correlation coefficients of selection and outcome regressions within the system, indicating the existence of joint determination of income and nutritional deprivation. The null hypothesis that these coefficients are jointly zero is firmly rejected in all specifications in Table 3 at the $1 \%$ significance level. This justifies the presumption on the structure of the variance-covariance matrix underlying the usefulness of our generalised selection model (1)-(9), with jointly distributed disturbances within and between poverty dimensions. It is also worth noting that the correlation coefficients between income and nutrition deprivations, $\hat{\rho}_{\varepsilon_{1} \varepsilon_{2}} \hat{\rho}_{v_{1} v_{2}}$, are positive in all specifications. This points to interdependent income poverty and malnutrition. We cannot tell from the data precisely what reasons underpin this interdependency, but one possible interpretation could be that it arises as a result of latent capabilities which underlie both income generation and nutrient intake. Again similar results as the two-step estimation are obtained but with smaller standard errors. Specifically, there were no age effects in household multi-dimensional intertemporal poverty. ${ }^{26}$ A doubled initial proportion of children and the elderly within the household (dependency ratio variable) would add $0.155-0.223$ to its intertemporal nutritional deprivation (Columns 5-8 of Table 2, Columns $5-6$ of Table 3). Having at least one ethnic family member in 2000 was associated with 0.232-0.572 lower subsequent intertemporal nutritional poverty (Columns 5, 6 and 8 of Tables 2, Columns 4-6 of Table 3), as the mean household per capita nutritional intake in 2000 was $51.4 \%$ higher in ethnic minorities than in Han people. ${ }^{27}$ The negative association with being from an ethnic minority and intertemporal nutritional deprivation also echoes the lower levels of average nutritional intertemporal deprivation measures for ethnic minorities

prices of different subsets of food items or log prices as the excluded restriction in the selection equation and re-estimated Columns 7 and 8 of Table 2. The estimated inverse Mills' ratio remains broadly the same between -0.793 and -0.695 - and is always statistically significant at the $1 \%$ level.

${ }^{25}$ We also re-estimated Columns 4 and 8 by classical Tobit regressions. In the interests of space, full results including these, and all log-likelihoods, are available from the authors upon request. Compared with Heckman by ML estimation, Tobit regression has poorer goodness-of-fit; log-likelihood decreases from -283.91 in Heckman (Column 4 of Table 2) to -288.013 in Tobit in the income dimension, and from -588.409 (Column 8 of Table 4 ) to -980.03 in the nutrition dimension. Statistical significance of a few variables differs between Tobit and Heckman regressions; e.g. the Tobit specification suggests an insignificant poverty-reducing impact of distance to primary school in the income dimension, but significant povertyreducing impact of distance to hospitals in the nutrition dimension. Such differences likely arise from biases in the classical Tobit due to not correcting for endogenous 'selection' into poverty.

${ }^{26} \mathrm{We}$ also inserted the squared term of age and re-estimated Table 2, but neither age variable was found to be statistically significant. The age of the household head varied from 22.5 (25) to 66.5 (70) in 2000 (2004), with the mean being 41.595 (45.031) in 2000 (2004). It seems that insignificant age impact is not due to lack of variation of age.

${ }^{27}$ The ethnic minorities in study provinces are basically Mongolian and Hui. Their higher nutritional intake than that of Han people may be caused by their traditional diet preference and structure dominated by milk, other dairy-products and meat. 
in Table 1. Moreover, given that the share of ethnic minorities differs between Gansu (97\%) and Inner Mongolia (87.9\%) at the $1 \%$ significance level, we further inserted a provincial dummy ( $1=$ Inner Mongolia) and its interaction with the dummy of ethnic minorities and re-estimated Columns 3 and 6 of Table 3. Neither the provincial nor ethnic dummy itself is statistically significant, while their interaction is 0.183 in the income dimension and -0.444 in the nutrition dimension, both at the $1 \%$ significance levels. Ethnic minorities in Inner Mongolia appear to suffer from higher income but lower nutrition intertemporal deprivations than their ethnic counterparts in Gansu. Neither dependency ratio nor ethnic status has a robust association with income deprivation.

Human capital, as captured by the sum of household labour force weighted by their years of education, robustly dampens intertemporal income deprivation with the marginal impact of 0.002-0.004 at the 1\% significance level (Columns 1-4 of Table 2 and Columns 1-3 of Table 3), but tends to raise intertemporal nutritional deprivation by a larger marginal amount of $0.004-0.008$ at the $1 \%$ significance level (Columns 5-6 of Table 4 and Column 4 of Table $3)$. This may be understandable, considering that more initial human capital, especially primary education, promotes income growth for Chinese rural households in lagging regions (e.g., Sato, 2010; Song, 2012), which is in turn associated with a dietary shift towards low total calorie intake and unhealthier food consumption through a negative income effect (e.g., Du et al. 2004). Moreover, insufficient diets and micronutrient supplementation, unsatisfactory or even non-existent catering infrastructure in rural schools, and misaligned supply-side incentives for health improvement programmes in rural China have been widely criticised as resulting in high prevalence of malnutrition among rural students (e.g., Kleiman-Weiner et al. 2012; Luo et al. 2011; Miller et al. 2012), undermining human capital formation and resulting in undernutrition during adulthood.

Initial physical capital, which is proxied by households' fixed productive assets, also appears to be associated positively with subsequent intertemporal nutritional deprivation (Column 8 of Table 2 and Columns 5-6 of Table 3). However, its net outcome is still negative (poverty-reducing), considering the larger negative impact of households' intertemporal average asset holdings. The statistically significant and negative estimates of initial productive assets in Columns 5-6 of Table 2, when the intertemporal asset holdings are not purged, also offer support for the view of a net poverty-reducing influence of productive asset accumulation. We observed similar phenomena for the role of land in both poverty dimensions. Having more areas of cultivated land owned by the household is associated with a net benefit to reducing intertemporal deprivations in both dimensions. This stems from having more land holdings in the long term, represented by a higher intertemporal mean farm size, rather than more initial land endowments. ${ }^{28}$

Initial labour productivity correlates negatively with both intertemporal income and nutritional deprivations at the $1 \%$ significance level $(-0.117$ and -0.052 in Columns 1 and 5 of Table 2, respectively). We further disaggregate this into three kinds of production arrangement commonly practised by rural households, namely (local) agriculture, local

\footnotetext{
${ }^{28}$ The positive correlation between intertemporal deprivations and initial land and asset holdings may be caused by the temporal increase of poverty from 2000 to 2001 which was discussed in Section 3. Its explanation may also apply to the positive, but insignificant, correlation between intertemporal poverty and initial agricultural labour productivity. However, the importance of agriculture cannot be simply denied, given its significant poverty-reducing effects through rural households' capacity building in agricultural production.
} 


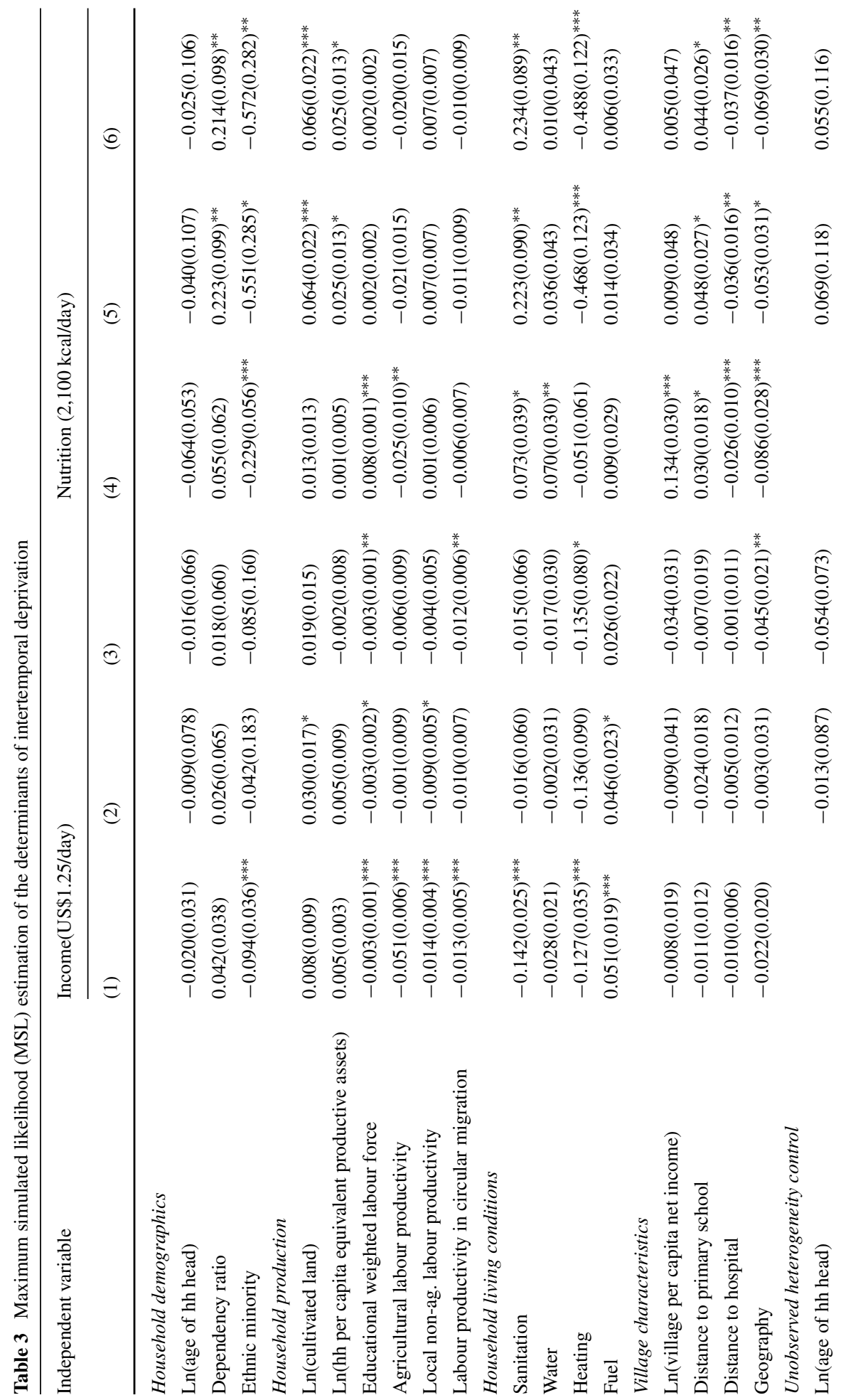




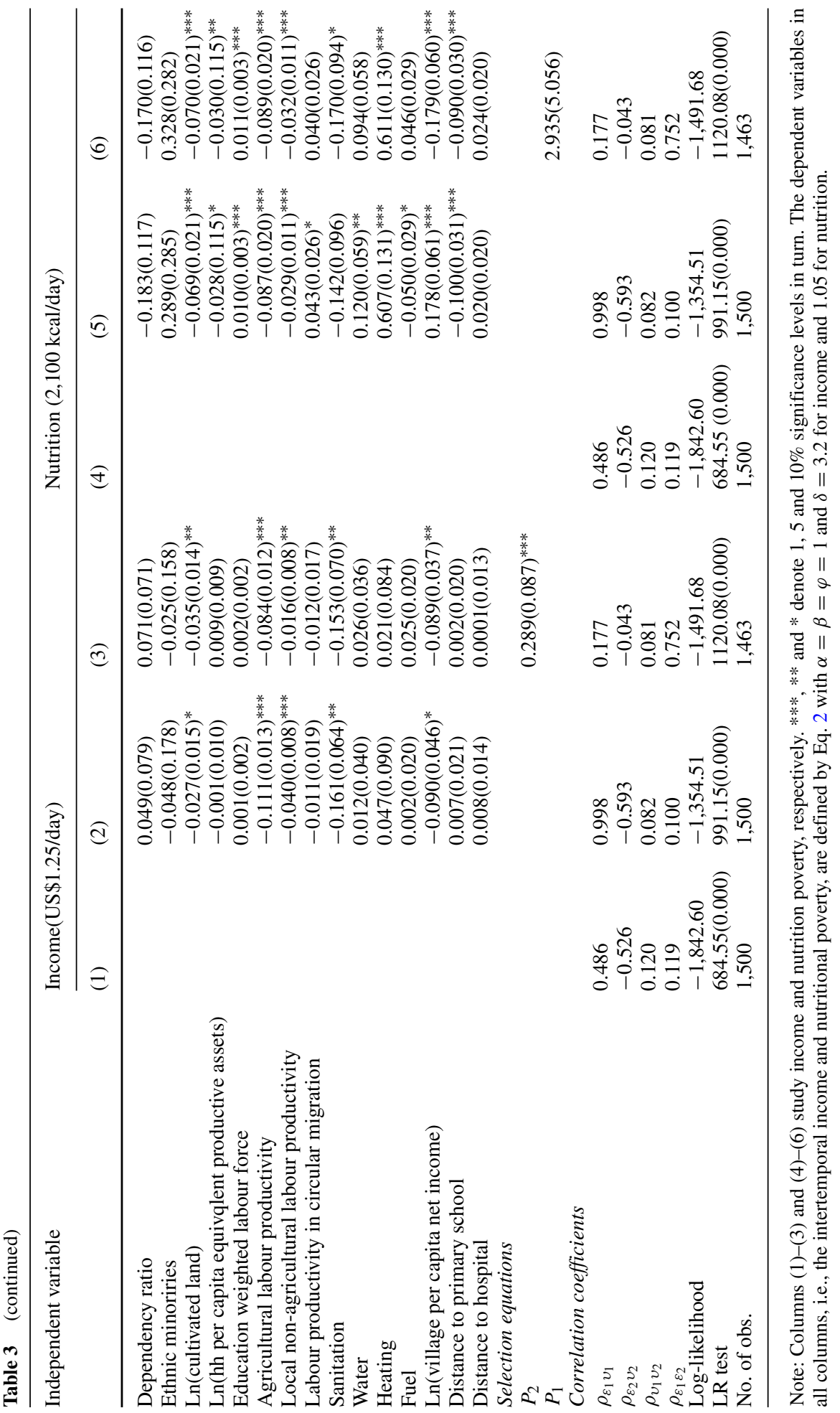


non-agriculture and circular migration. ${ }^{29}$ A $10 \%$ increase in initial agricultural labour productivity, measured by the net agricultural income (yuan) per agricultural labour input (day), would suppress $0.0036-0.0051$ of the household's subsequent intertemporal income deprivation (Column 2 of Table 2 and Column 1 of Table 3), and 0.0025 of its intertemporal nutritional deprivation (Column 4 of Table 3). The magnitude of the above reductions is equivalent to $5.7-8.1 \%(0.0036 / 0.063$ and $0.0051 / 0.063)$ and $0.48 \%(0.0025 / 0.521)$ of the average intertemporal income and nutrition deprivations, respectively, across all households. Note that statistical significance of the initial agricultural labour productivity gives way to that of its intertemporal mean (Columns 3-4 and 7-8 of Table 2, Columns 2-3 and 5-6 of Table 3). The magnitude of marginal decreases in intertemporal deprivation brought by a $10 \%$ increase in households' intertemporal mean agricultural productivity also rose to as much as 0.0125 for income (Column 4 of Table 2), equivalent to a $16 \%(0.0125 / 0.063)$ decrease in average intertemporal income deprivation, and 0.009 for nutrition (Column 6 of Table 3), equivalent to a $2 \%(0.009 / 0.521)$ decrease in average intertemporal nutritional deprivation. This implies that households' long-term growth in agricultural labour productivity functions as a more effective instrument to fight against intertemporal income and nutritional deprivations in the course of poverty transitions than do short-term increases, or simply a higher initial endowment, of agricultural labour productivity. The long-term benefit of agricultural improvement is consistent with other empirical findings. In respect of poverty transitions over time in rural China, agriculture prevents re-entry into poverty for those who have recently escaped and engaged mainly in out-migration (Imai and You, 2014), by assuring them of some safety nets for subsistence livelihood when shocks and uncertainties hit (Wang et al. 2013).

Local non-agricultural activities also appear to reduce intertemporal income as well as nutritional deprivations in both Heckman (Table 2) and generalised selection models (Table 3). The impact on the former is felt through both initial and intertemporal improvement in labour productivity in local non-agricultural production, while the impact on the latter is realised only when long-term improvement is achieved. If referring to the average level of income and nutritional intertemporal deprivations as listed in Table 1, a 10\% increase in initial local non-agricultural labour productivity can yield about $6 \%(0.004 / 0.063$ in Column 2 of Table 3) and $0.6 \%(0.003 / 0.521$ in Column 6 of Table 3) reductions in intertemporal income and nutritional deprivations, respectively, both of which are the same or smaller than those brought by equivalent gains in either short- or long-term agricultural labour productivity.

In contrast, circular migration only suggests a significant income poverty-reducing effect through its initial rather than long-term level, which is indicated by statistically insignificant estimates of intertemporal mean variables in Columns 3-4 of Table 2 and Columns 2-3 of Table 3, and does not help improve nutrition. As previously shown in Table 3, households relying most on circular migration endure the severest intertemporal poverty among three different livelihood groups, especially at lower poverty lines and in the income dimension. This might be explained by the mixed role of migration in poverty dynamics. From a static point of view, migration helps households escape from monetary poverty as it brings more income and consumption particularly for the poor (de Brauw and Giles, 2012). Recalculating Table C.1 in Appendix C for households, respectively, ever with and always without, out-migrating family members between 2000 and 2004, we find that the average

\footnotetext{
${ }^{29}$ Circular migration in rural areas refers to working, or seeking jobs temporarily, outside of the residence village but with registration being attached to the original household.
} 
probability of escaping income deprivation against US $\$ 1.25 /$ day across two consecutive waves is $80.1 \%$ for the former group as opposed to $67.1 \%$ for the latter. Nevertheless, when accounting for dynamic aspects of poverty, such as transitions, migration may also incur the risk of repeated poverty, especially for those living without any agricultural production, possibly due to various uncertainties and economic risk in underdeveloped factor markets (Imai and You, 2014) and no investment effect of migration on households' productive activities (de Brauw and Giles, 2012). In our data, 37.6\% of households with out-migrating family members, and which have ever managed to escape income poverty, remained successfully above the poverty line throughout the sample period; $25.2 \%$ managed to stay in non-poverty in just one wave. By contrast, $43.1 \%$ of those without any out-migrating family members, but having ever escaped income poverty, maintained their non-poverty status throughout the sample period and only $20.7 \%$ were non-poor in just one wave.

The insensitivity of household nutrient intake to migration could be explained by the structure of household consumption expenditure when more income is generated by circular out-migration. Although our dataset did not record how or where the households used remittances, previous studies and some cross-tabulations of our data may provide some clues. Specifically, in a household survey in six provinces in 2000, de Brauw and Rozelle (2008) find that in relatively affluent areas, where the median incomes were more than twice the poverty line, an additional migrant increased investment in housing and consumer durables by $20 \%$, while there was no association between remittances and productive investment in remaining households in the village. The much stronger propensity to consume, in particular to construct houses, compared to saving on receipt of remittances, is reaffirmed by Zhu et al.'s (2012) study based on another survey in 2006. They further document even less savings for productive investment in both agriculture and household business in migrant, than in non-migrant, families. Our data from two poor provinces also lend support to these findings. The correlation coefficient between households' real food consumption per adult equivalent and out-migration (i.e., a dummy variable taking the value of 1 for migrant households) is -0.174 . Conversely, a $1 \%$ increase in household incomes of migrants is associated with a $0.1 \%$ increase in the real value of the house, at the 5\% significance level. Compared with non-migrant households, migrant households lived in better houses, with 3.84 more squared metres of brick areas, at the $10 \%$ significance level. ${ }^{30}$

Comparing the above three livelihood arrangements, the magnitude of the impact of initial agricultural labour productivity on reducing intertemporal deprivations is significantly larger than that of local non-agriculture activities and circular migration: the Wald test of equal estimated coefficients for the three kinds of labour productivity in Column 2 of Table 2 and Column 1 of Table 3 is firmly rejected at $1 \%$ significance level with $\chi^{2}(2)$ being 15.14 and 38.23 , respectively.

Our finding of the crucial role of agriculture in fighting against poverty echoes the recent resurgent discussion on agriculture in developing countries (e.g., de Janvry and Sadoulet, 2010 for summary arguments with Vietnam as an example; Ravallion, 2009 for rural China; Dethier and Effenberger, 2012 for a recent literature review), especially for the poorest of the

\footnotetext{
${ }^{30}$ The estimates in this and previous sentences are obtained by the following household fixed-effect instrumental variable estimation. We regressed the natural logarithm of the real value of the house (the squared metres of housing areas constructed by bricks) on the natural logarithm of real household incomes from circular migration (the dummy variable taking the value of 1 for migrant households), which was instrumented by its average at the village level in each wave, and other covariates including the household size measured by the equivalent adults, the dependency ratio, ethnicity, gender, age and education of the household head, village and wave dummies, and the household fixed effects.
} 


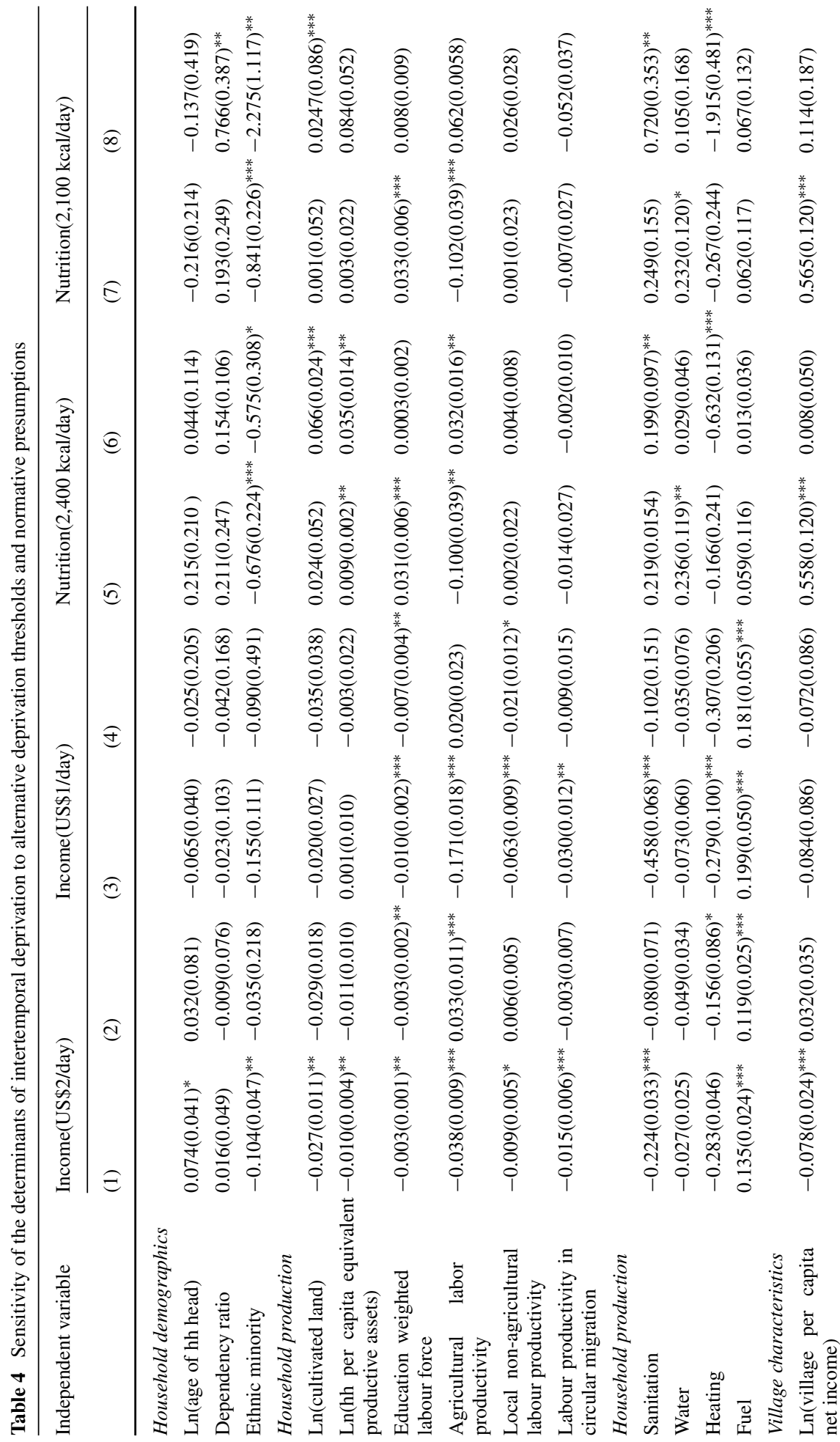




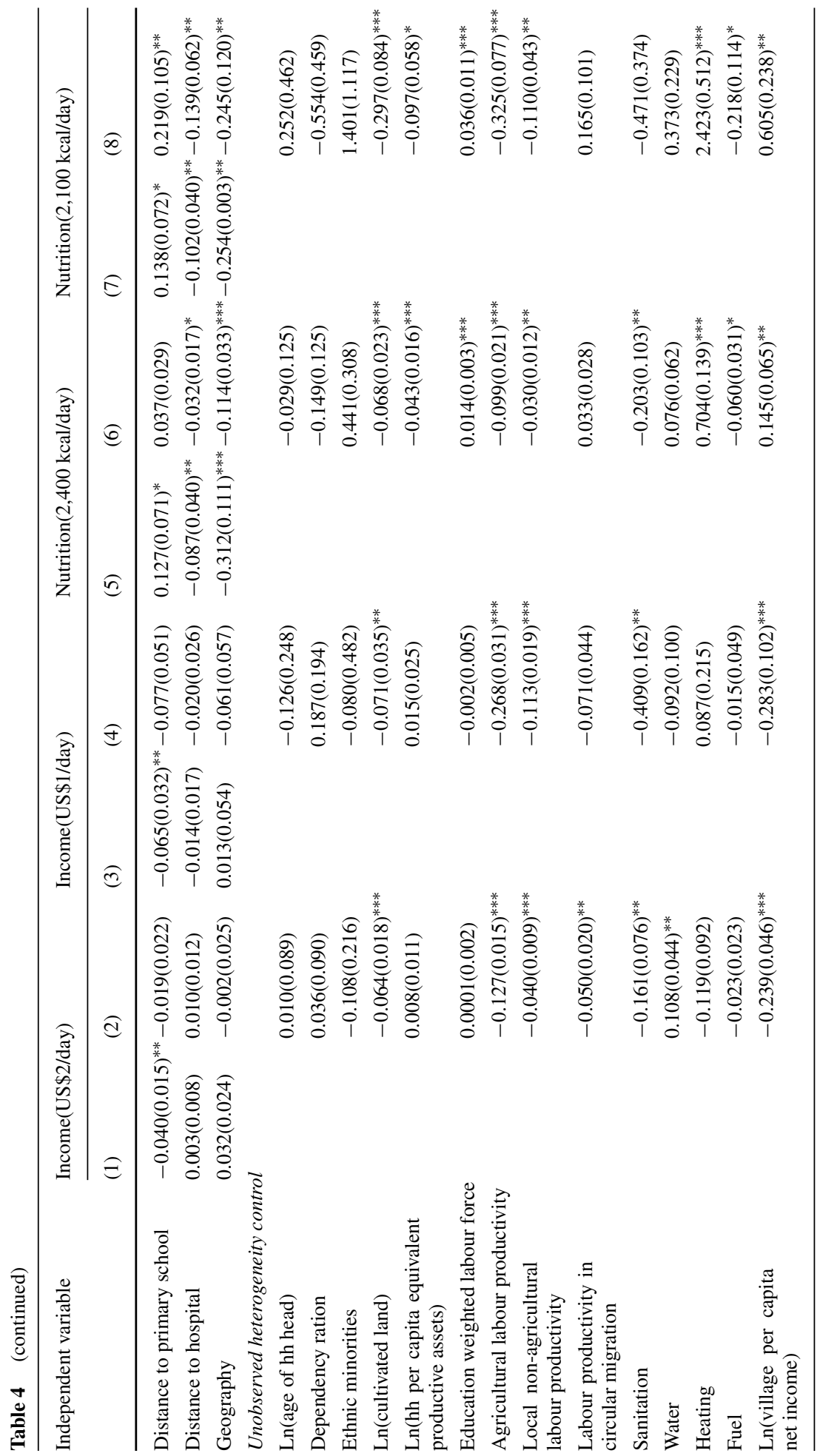




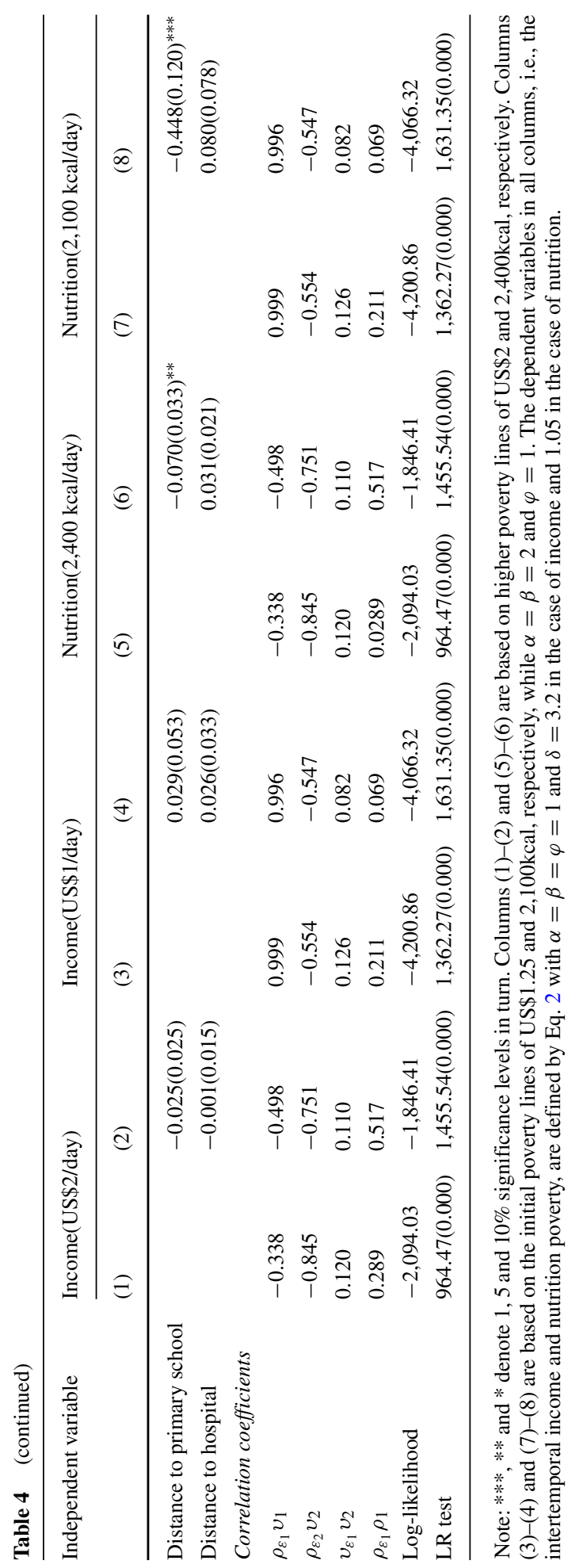


poor (Christiaensen et al. 2011). For rural China in particular, at the national and provincial levels, the agricultural sector alone contributes to $75-80 \%$ of the drop in national poverty incidence (Ravallion and Chen, 2007) as opposed to little influence from manufacturing and services industries (Montalvo and Ravallion, 2010). At the household level, as in the macrolevel studies, Christiaensen et al. (2013) use the same dataset as ours and also find that local agricultural production per se provides the most effective pathway out of poverty in the early stage of development. Agricultural labour productivity is the largest of three kinds of labour input and suggests the highest elasticity of poverty ( -0.53 for Inner Mongolia and -0.73 for Gansu) compared to local diversification to non-agricultural sectors $(-0.07$ and -0.16 for two provinces, respectively) and circular migration $(-0.01$ and -0.09 for two provinces, respectively).

At the village level, the long-term higher average village income is associated strongly with lower intertemporal income poverty, but higher nutritional deprivation (Columns 4 and 8 of Table 2 and Columns 2-3 and 5-6 of Table 3), which again could be on account of the negative income effect on household nutrition. The longer the distance to education and health services, the lower the intertemporal income and nutritional poverty, either in the short- or long-term or the net of the two effects. We suspect that this may be because schools and hospitals at greater distance are of better quality, as the Chinese government launched a campaign in rural areas from 2001 which dismantled village schools in remote areas and combined them with those in towns or counties, in order to provide better quality educational services for rural students. ${ }^{31}$ Hospitals in towns and counties are also generally equipped with more qualified doctors and better facilities than village clinics.

In addition, we re-estimated Tables 2 and 3 with more kinds of infrastructures, including the proportion of villages in the county with access to electricity, roads and TV signals. However, none of them were statistically significant. This is worrying, as villagetargeted investment projects, and aid which goes mainly to infrastructure, have long been a major theme of policy intervention in rural China. At least in the intertemporal respect, many village-level infrastructure investments appear not to be an effective instrument for alleviating poverty.

\subsection{Robustness checks}

We check the robustness of our findings to alternative deprivation thresholds, normative assumptions of influence of poor and affluent spells during transitions, and intertemporal deprivation measures. Specifically, we re-estimated simultaneously all equations within the system with inter-dependent random errors (i.e., Columns 1-2 and 4-5 of Table 3) under higher poverty lines of US\$2/day and 2,400 kcal for income and nutritional dimensions, respectively. Results are reported in Columns (1)-(9) and (4)-(5) of Table 4. We also replaced linear intensification and mitigation effects $(\alpha=\beta=\varphi=1)$ with an increased

\footnotetext{
${ }^{31}$ It is notable that although nutritional poverty-reducing in the long-term, longer distance to the primary school is likely to raise intertemporal nutritional poverty in the short-term, reflected by significantly positive estimates of initial distance to primary schools in Columns 6-8 of Table 2 and 4-6 of Table 3 . This may be ascribable to low quality of school meals and misaligned incentives of school heads to supply nutrition-rich and healthy diets in rural China, as cited before in Kleiman-Weiner et al. (2012), Luo et al. (2011) and Miller et al. (2012).
} 
influence of both households' past poor and past affluent experiences $(\alpha=\beta=2 ; \varphi=1)$. These results are reported in Columns (2)-(3) and (6)-(7) of Table $4 .{ }^{32}$

Many of the aforementioned effects still hold, while some are either reinforced or diminished. For example, labour productivity gains in local non-agricultural and circular migration become a significant driving force in suppressing not only intertemporal income poverty, but also in the nutritional dimension (Columns 5-8 of Table 4). More land cultivated by the household in the long-term is also strongly and negatively associated with both income and nutritional poverty, and the magnitude dominates the short-term povertyincreasing effects stemming from an initially larger farm size (Columns 2, 4, 6 and 8 of Table 4). The dependency ratio, in general, loses statistical significance, while the magnitude of ethnic distinction becomes more salient in both income and nutritional dimensions, with ethnic minorities being less poor intertemporally.

We were also concerned with the impact of the normative assumptions of our intertemporal poverty measures, that is, how our findings might differ when considering simply incidence of non-poverty (i.e. assigning the same mitigating value to all non-poverty spells regardless of the extent of affluence), versus allowing an enhanced mitigating effect of non-poor spells which are far above the deprivation line. We re-estimated Table 3 under "standard" thresholds of US\$1.25/day and 2,100 kcal/day for income and nutritional dimensions, respectively, but replaced the dependent variables with the constant-relative affluence-dependent intertemporal deprivation measure, i.e., Eq. 1 with $\alpha=\beta=\varphi=1$. Table 5 reports new estimates. By comparing Columns (1)-(9) and (4)-(5) between Tables 3 and 5, it can be seen that our previous findings hold broadly under the constant-relative measures.

It is also worth noting that caloric intake is not as perfectly transferable as income is. One cannot easily store past caloric intake and "withdraw" it in later nutrition-poor periods for the purpose of compensation (see also Behrman et al. 1997). Considering the above differences between income and caloric intake, we estimate relative affluence-dependent intertemporal measure in Column 4 (i.e., $\tilde{P}_{R}$ allowing for compensation) jointly with the constant-relative affluence-dependent intertemporal measure in the nutrition dimension (i.e., $P_{R}$ without compensation) in Column 8 of Table 5. Again this yields similar results.

\subsection{Interlocked poverty and nutritional intertemporal poverty}

In addition to common unobserved factors and shocks affecting jointly household income and nutrient intake (i.e., simultaneity), we also consider the possible two-way effects between the two kinds of poverty (i.e., recursion). It has been well-established in theory that malnutrition can undermine individuals' income generating capability by deterring human capital accumulation, and that low income can, in turn, worsen nutritional status (Dasgupta and Ray, 1986). The two-way effects constitute nutritional poverty traps. Empirical evidence has been found in India (Jha et al. 2009), but remains scarce for rural China (even taking a static approach to poverty measurement, let alone in an intertemporal perspective).

\footnotetext{
${ }^{32}$ We also checked the sensitivity of results by assigning higher values to $\delta$ (i.e., defining "absolute affluence" as those in at least the $80^{\text {th }}$ or $85^{\text {th }}$ income or nutrition percentile) while keeping other parameters the same as before in $\tilde{P}_{R}$. Compared with Table 1, the new multi-dimensional intertemporal poverty measures only differ from the $2^{\text {nd }}$ decimal places. As such, re-estimating Table 3 with these new measures does not yield significant changes in results.
} 
We revise the system (1-2) with inter-dependent random errors to reflect possibly mutually determined income and nutritional deprivations. The selection equations in the system are replaced by recursive ones, as follows:

$$
\begin{aligned}
& y_{1}^{*}=\mathbf{x}^{\prime} \theta_{1}+\overline{\mathbf{x}}^{\prime} \theta_{2}+\mathbf{z}_{1}^{\prime} \theta_{3}+\gamma_{2} p_{2}+\varepsilon_{1} \\
& y_{2}^{*}=\mathbf{x}^{\prime} \theta_{1}+\overline{\mathbf{x}}^{\prime} \theta_{2}+\mathbf{z}_{2}^{\prime} \theta_{3}+\gamma_{1} p_{1}+\varepsilon_{2}
\end{aligned}
$$

As such, the latent variable $y_{1}^{*}$, which determines a household's per-period observed income deprivation incidence, is affected by its intertemporal nutritional deprivation $p_{2}$, and vice versa. ${ }^{33}$ At the same time, the error terms within the whole system are still jointly distributed, $(\boldsymbol{\varepsilon}, \boldsymbol{v}) \mid \mathbf{x} \bar{x} \mathbf{z} \sim N I D(0, \boldsymbol{\Sigma})$. This recursive system can be estimated consistently by MSL (Roodman, 2011).

There appears to be an intertemporally inter-locked vicious circle between income and nutrition. Columns (3) and (6) of Table 3 report the estimation results. The estimates are broadly the same as in our previous findings. It is noticeable that $\hat{\gamma}_{2}$ in Eq. 7 is positive at the $1 \%$ significance level, and implies that a unit increase in the magnitude of intertemporal nutritional poverty can make households 28.9 percentage points more likely to fall below the US\$1.25-a-day poverty line in at least one year. The probability of falling below the nutritional threshold of 2,100 kcal per person per day is nearly quadrupled (2.935) under an additional unit of intertemporal income deprivation, though the effect lacks statistical significance. Intertemporally higher labour productivities in agriculture or local non-agricultural production exhibit poverty-reducing effects in both dimensions (as shown by Columns 3 and 6 of Table 3) even in the presence of intertemporal income-nutrition poverty traps, while outmigration only suggests short-term income-poverty alleviating effect through households' higher initial labour productivity in out-migration (Column 3 of Table 3).

This intertemporal relationship between income and nutritional deprivations also exists under the $\tilde{P}_{R}$ measures, as shown in Columns (2) and (5) of Table 5. Moreover, the impact of intertemporal nutritional deprivation on intertemporal income deprivation becomes larger (from 28.9 to 42.9 percentage points) as the absolute affluence in non-poverty spells mitigates deprivation less under $P_{R}(\gamma=1)$ than under $\tilde{P}_{R}(\gamma=2)$ in). Nevertheless, it is worth noting that the short-term intertemporal poverty-reducing effect of initial labour productivity gains in out-migration disappears (Column 3 of Table 3 vs. Column 3 of Table 5), while the initial labour productivity gains in local non-agriculture mitigate intertemporal income deprivation in all specifications (Columns 1-3 of Table 5). Out-migration realises its substantial poverty-reducing effect only in the long-term $(-0.178$ at the $5 \%$ significance level in Column 3 of Table 5), and is nearly four times as large as that of the gains in agriculture $(-0.045$ at the $1 \%$ significance level in Column 3 of Table 5). This contrasts with the insignificant long-term effect of out-migration on $\tilde{P}_{R}$ in Column 3 of Table 3 . This sharp difference reaffirms our previous argument that out-migration could be a quicker means to lifting income above the poverty line than agriculture. However, when taking the extent of affluence as a long-term consequence of different livelihood arrangements, the average household net income per adult equivalent was 12-16\% lower in those having ever engaged in out-migration than in those still implementing agricultural production in different waves.

\footnotetext{
${ }^{33}$ It is likely that nutrition and income deprivations affect each other dynamically in the long-term, i.e., with time lags. Nevertheless, as mentioned in Footnote 12, given the intertemporal nature of the measures for the entire period and the definitions of $y_{j}$, we cannot take into account sequences of deprivation transitions within or between dimensions. This invites separate analysis and is beyond the scope of this study. Therefore, the analysis here can be more safely understood as providing evidence of strong intertemporal correlation between deprivations in two dimensions, which is likely to generate intertemporal causation.
} 


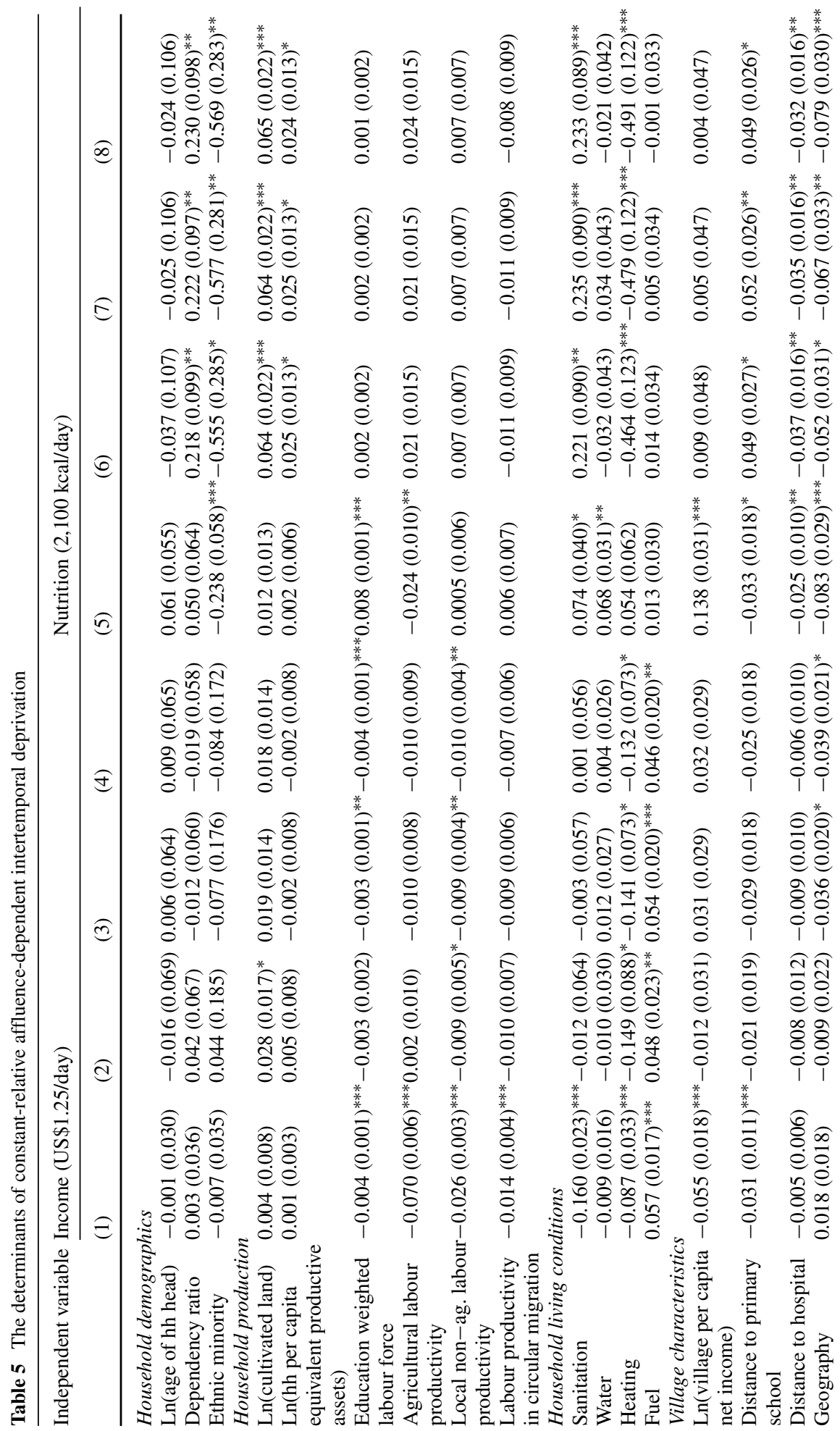




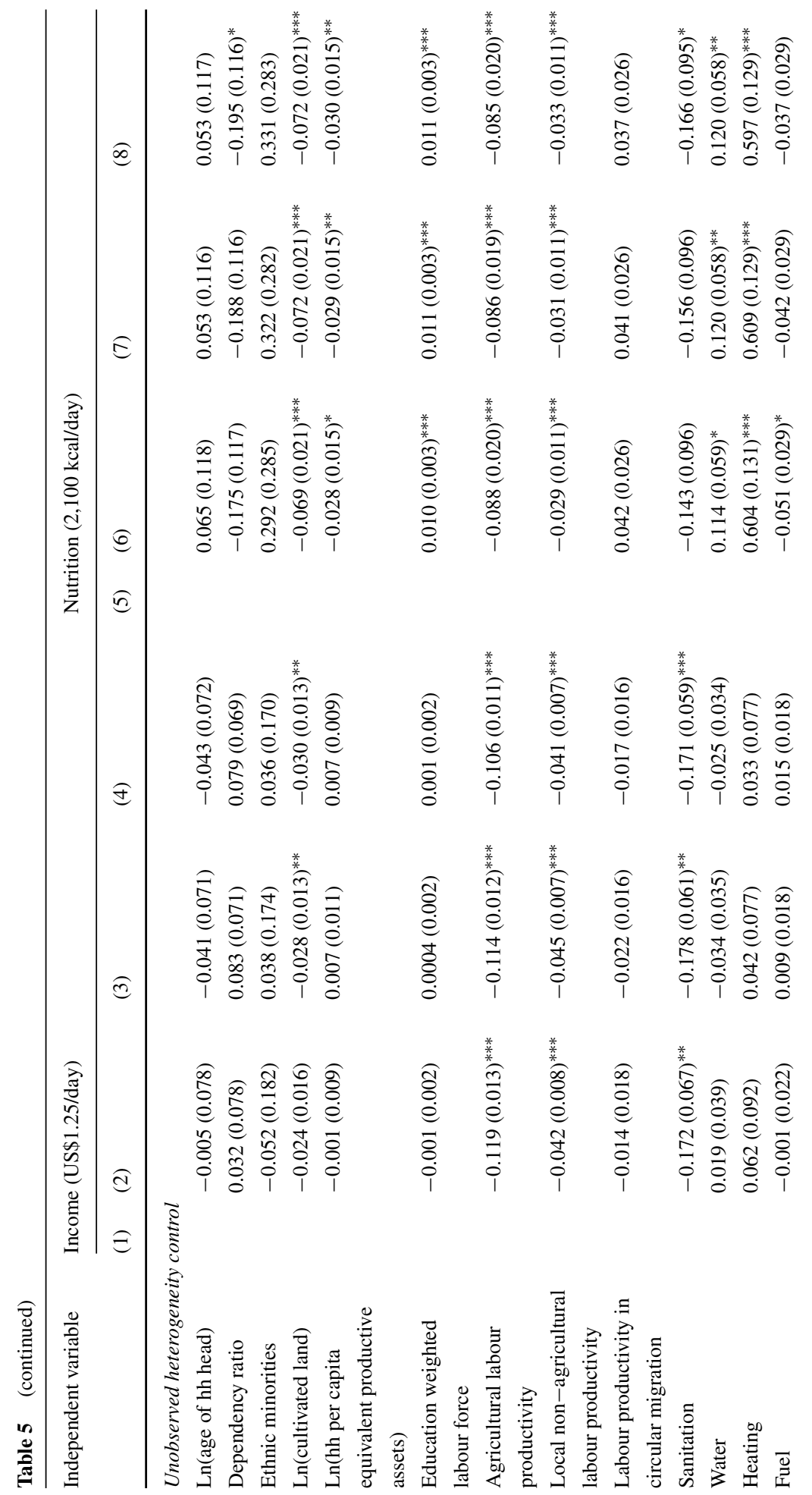




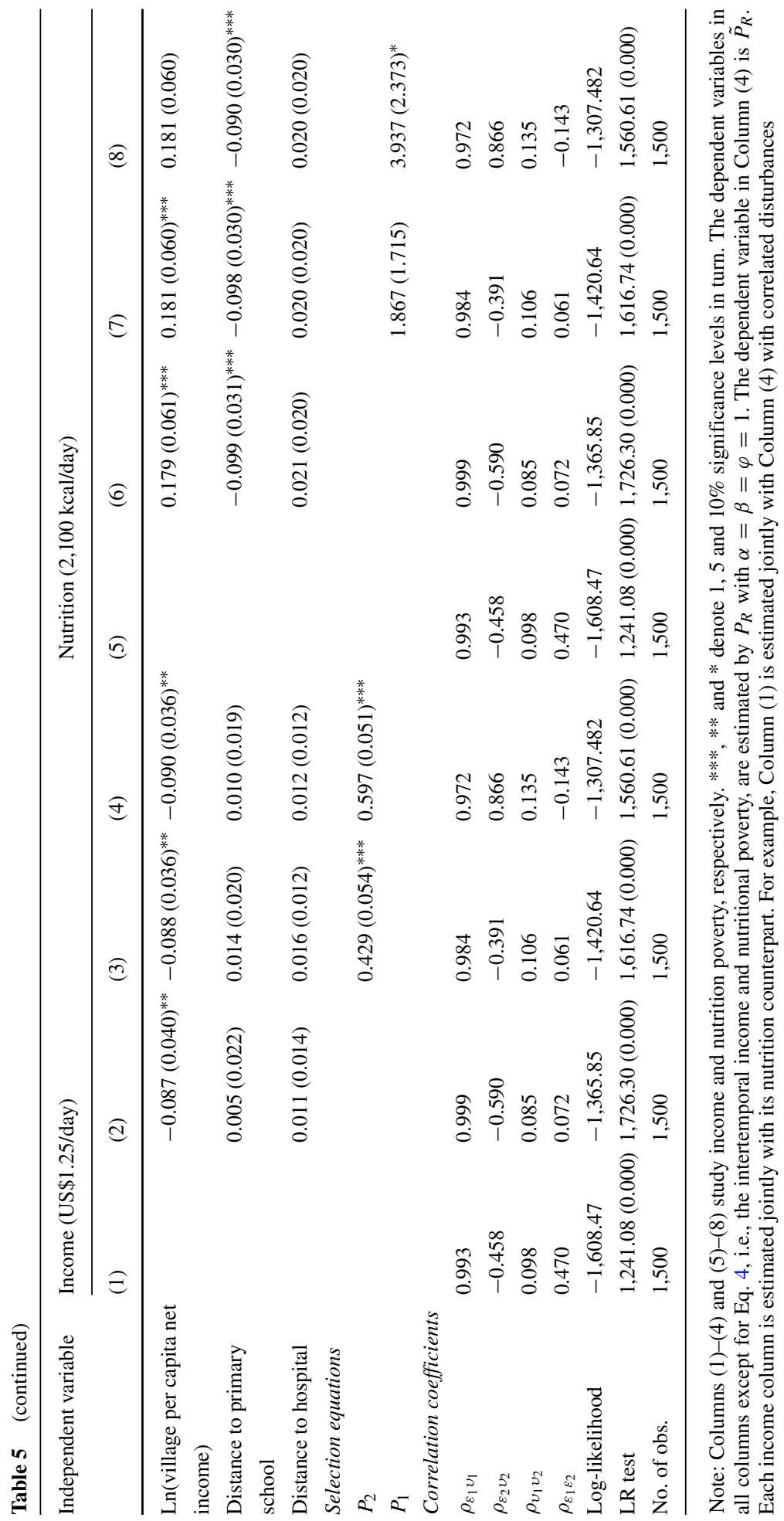


As noted above, this is possibly due to various risks and uncertainties in urban labour markets.

\section{Conclusion}

By exploiting a household panel dataset in poor rural areas in China over the period 2000 2004, we estimate household intertemporal deprivation in both income and nutritional dimensions and identify various social and economic factors which appear to help shape household intertemporal deprivation profiles in at least two important dimensions.

Methodologically, we apply Dutta et al.'s (2013) affluence-dependent intertemporal poverty measures and propose a generalised selection system, together with an extension that helps to detect intertemporally interlocking deprivations across dimensions. While the focus in this paper is on just two dimensions, our generalised and recursive selection approach can readily be extended to more dimensions. Strictly exogenous instrumental variables are not a necessity. The model can yield consistent estimates under correlated and jointly distributed disturbances, although weakly exogenous instrumental variables for each dimension would help improve identification. Another appealing extension of our model is that the dependent variables need not necessarily be binary, but could be continuous or categorical variables, to capture deprivations with different properties. In this case, one would only need to change the variance-covariance matrix of the disturbances in accordance with the new dependent variables to obtain consistent estimation. The estimated variancecovariance matrix of jointly distributed disturbances reveals interdependent income poverty and malnutrition in Gansu and Inner Mongolia.

To the extent that intertemporal poverty is the focus of policy makers our evidence suggests that household-focused interventions generally outperform village-level instruments. In the early stages of development, and when agriculture is a dominant element of individuals' livelihood, improvement in agricultural production, both in terms of increased agricultural labour productivity and of larger farm size and investment in productive assets, still holds the key to reducing both intertemporal income and nutritional deprivations. This is true whether focusing on the poorest of the poor, or when the richer poor are also included, by adopting higher deprivation thresholds. The finding is also robust across different normative assumptions underlying intertemporal deprivation aggregation over time. Furthermore, when there is evidence suggestive of intertemporal income-nutrition traps, higher labour productivity in agriculture in the long-term holds more potential for breaking the vicious circle, in both income and nutritional dimensions, than does local non-agricultural production or out-migration. However, long-term labour productivity gains in out-migration dominate agriculture in reducing intertemporal income deprivation if only incidence, rather than the extent, of affluence prior to poverty spells, is embedded in the intertemporal measure.

Our results suggest that the purported positive roles of local non-agricultural production and out-migration in reducing monetary poverty might be overblown, at least as an intertemporal phenomenon. They are not magic bullets. Rather, whatever effect they have on both income and nutritional dimensions is likely to be highly context specific and dependent on other factors.

Acknowledgments The authors are extremely grateful to Stephan Klasen and Christophe Muller, for helpful comments on an earlier draft. The paper has also benefitted from helpful discussions with a number of participants at the International Conference "Poverty, Equity, and Growth in Developing and Transition Countries", held jointly by the Courant Research Center and the Ibero-America Institute of Economic 
Research, at the University of Göttingen during 2-4 July 2014, and the Annual Conference of the Chinese Economic Association (Europe) held during 1-2 September 2014 at the University of Göthenburg. The usual caveats, of course, apply. Finally, we wish to gratefully acknowledge generous financial support by the National Natural Science Foundation of China (Grant No.: 71403282 and 71673283) and the National Social Science Foundation of China (Grant No.: 15ZDC026).

Open Access This article is distributed under the terms of the Creative Commons Attribution 4.0 International License (http://creativecommons.org/licenses/by/4.0/), which permits unrestricted use, distribution, and reproduction in any medium, provided you give appropriate credit to the original author(s) and the source, provide a link to the Creative Commons license, and indicate if changes were made.

\section{References}

Alkire, S., Foster, J.: Counting and multidimensional poverty measure. J. Publ. Econ. 95(7-8), 476-487 (2011a)

Alkire, S., Foster, J.: Understandings and misunderstandings of multidimensional poverty measurement. J. Econ. Inequal. 9, 289-314 (2011b)

Alkire, S., Santos, M.E.: Acute multidimensional poverty: a new index for developing countries. OPHI working paper series, pp. 38 (2011)

Alkire, S., Apablaza, M., Chakravarty, S., Yalonetzky, G.: Measuring chronic multidimensional poverty: A counting approach. Paper presented at the IARIW-IBGE Conference on Income, pp. 11-14. Wealth and Well-Being in Latin America, Rio de Janeiro, Brazil (2013)

Atkinson, A.: Multidimensional deprivation. Contrasting social welfare and counting approaches. J. Econ. Inequal. 1, 51-65 (2003)

Baulch, B., Hoddinott, J.: Economic mobility and poverty dynamics in developing countries. J. Dev. Stud. 36(5), 1-24 (2000)

Behrman, J.R., Foster, A.D., Rosenzweig, M.R.: The dynamics of agricultural production and the calorieincome relationship: Evidence from Pakistan. J. Econ. 77(1), 187-207 (1997)

Bliss, C.J., Stern, N.H.: Productivity, wages and nutrition: Theory and observations. J. Dev. Econ. 5, 331-398 (1978)

Bossert, W., Chakravarty, S., D’Ambrosio, C.: Poverty and time. J. Econ. Inequal. 10(9), 145-162 (2012)

Bourguignon, F., Chakravarty, S.: The measurement of multidimensional poverty. J. Econ. Inequal. 1, 25-49 (2003)

Calvo, C., Dercon, S.: Chronic poverty and all that: The measurement of poverty over time. In: Addison, T., Hulme, D., Kanbur, R. (eds.) Poverty Dynamics: Interdisciplinary Perspectives, pp. 29-58. Oxford University Press, Oxford (2009)

Chamberlain, G.: Panel data. In: Griliches, Z., Intrilligator, M.D. (eds.) Handbook of Econometrics 2, pp. 1248-1318. Elsevier Science Publishers B.V., Amsterdam (1984)

Christiaensen, L., Demery, L., Kuhl, J.: The (evolving) role of agriculture in poverty reduction - an empirical perspective. J. Dev. Econ. 96(9), 239-254 (2011)

Christiaensen, L., Pan, L., Wang, S.: Pathways out of poverty in lagging regions: Evidence from rural western China. Agric. Econ. 44(1), 25-44 (2013)

D'Ambrosio, C.: The indicators of intertemporal material deprivation: A proposal and an application to EU countries. ImPRovE Discussion Paper No. 13/08. Antwerp (2013)

Dasgupta, P., Ray, D.: Inequality as a determinant of malnutrition and unemployment: Theory. Econ. J. 96(384), 1011-1034 (1986)

Dasgupta, P., Ray, D.: Inequality as a determinant of malnutrition and unemployment: Policy. Econ. J. 97, 177-188 (1987)

de Brauw, A., Giles, J.: Migrant labor markets and the welfare of rural households in the developing world: Evidence from China. IZA Discussion Paper, No. 6765 (2012)

de Brauw, A., Rozelle, S.: Migration and household investment in rural China. China Econ. Rev. 19(9), 320-335 (2008)

de Janvry, A., Sadoulet, E.: Agricultural growth and poverty reduction: Additional evidence. World Bank Res. Obs. 25(1), 1-20 (2010)

Dercon, S., Hoddinott, J.: Health, shocks and poverty persistence. In: Dercon, S. (ed.) Insurance Against Poverty. Oxford University Press, Oxford (2005) 
Dethier, J., Effenberger, A.: Agriculture and development: A brief review of the literature. Econ. Syst. 36(9), 175-205 (2012)

Du, S., Mroz, T.A., Zhai, F., Popkin, B.M.: Rapid income growth adversely affects diet quality in China particularly for the poor! Soc. Sci. Med. 59(7), 1505-1515 (2004)

Duclos, J., Araar, A., Giles, J.: Chronic and transient poverty: Measurement and estimation, with evidence from China. J. Dev. Econ. 91(9), 266-277 (2010)

Dutta, I., Roope, L., Zank, H.: On intertemporal poverty measures: The role of affluence and want. Soc. Choice Welf. 41(3), 741-762 (2013)

FAO: The state of food insecurity in the world: The multiple dimensions of food security. Rome, FAO (2013)

Foster, J.: A class of chronic poverty measures. In: Addison, T., Hulme, D., Kanbur, R. (eds.) Poverty Dynamics: Interdisciplinary Perspectives, pp. 59-76. Oxford University Press, Oxford (2009)

Gaiha, R., Kaicker, N., Imai, K.S., Kulkarni, V.S., Thapa, G.: Dietary shift and diet quality in India: an analysis based on the 50th, 61st and 66th rounds of the NSS. In: Jha, R., Gaiha, R., Deolalikar, A. (eds.) Handbook on Food: Demand, Supply, Sustainability and Security, pp. 177-203. Edward Elgar Publishing, Gloucestershire, UK (2014)

Gradín, C., Río, C.D., Cantó, O.: Measuring poverty accounting for time. Rev. Income Wealth 58(9), 330-354 (2012)

Heckman, J.: Sample selection bias as a specification error. Econometrica 47(1), 153-161 (1979)

Hoy, M., Zheng, B.: Measuring lifetime poverty. J. Econ. Theory 146(5), 2544-2562 (2011)

Imai, K., You, J.: Poverty dynamics of households in rural China. Oxford Bull. Econ. Stat. 76(5), 898-923 (2014)

Jalan, J., Ravallion, M.: Transient poverty in postreform rural China. J. Comp. Econ. 26(9), 338-357 (1998)

Jha, R., Gaiha, R., Sharma, A.: Calorie and micronutrient deprivation and poverty nutrition traps in rural India. World Dev. 37(4), 982-991 (2009)

Kleiman-Weiner, M., Luo, R., Zhang, L., Shi, Y., Martorell, R., Rozelle, S., Medina, A.: Multiple micronutrient supplementation reduces anemia anxiety in rural China's elementary school children. J. Nutr. 143(4), 640-647 (2012)

Labar, K., Bresson, F.: A multidimensional analysis of poverty in China from 1991 to 2006. China Econ. Rev. 22(3), 646-668 (2011)

Leibenstein, H.: Economic backwardness of economic growth. Wiley, New York (1957)

Luo, R., Zhang, L., Liu, C., Zhao, Q., Shi, Y., Miller, G., Yu, E., Sharbono, B., Medina, A., Rozelle, S., Martorell, R.: Anaemia among students of rural China's elementary schools: Prevalence and correlates in Ningxia and Qinghai's poor counties. J. Health Popul. Nutr. 29(4), 471-485 (2011)

McCulloch, N., Calandrino, M.: Vulnerability and chronic poverty in rural Sichuan. World Dev. 31(2), 611628 (2003)

Mendola, D., Busetta, A.: The importance of consecutive spells of poverty: A path-dependent index of longitudinal poverty. Rev. Income Wealth 58(9), 355-374 (2012)

Mendola, D., Busetta, A.: Chronic poverty in european mediterranean countries. In: Advances in Theoretical and Applied Statistics, pp. 339-350. Springer, Berlin Heidelberg (2013)

Miller, G., Luo, R., Zhang, L., Sylvia, S., Shi, Y., Foo, P., Zhao, Q., Martorell, R., Medina, A., Rozelle, S.: Effectiveness of provider incentives for anemia reduction in rural China: a cluster randomised trial. BMJ, 345 (e4809) doi:10.1136/bmj.e4809 (2012)

Montalvo, J., Ravallion, M.: The pattern of growth and poverty reduction in China. J. Comp. Econ. 38(1), 2-16 (2010)

NBS: Poverty monitoring report of rural china. department of household surveys national bureau of statistics of china. China Statistics Press, Beijing (2000)

Ogundari, K., Abdulai, A.: Examining the heterogeneity in calorie-income elasticities: A meta-analysis. Food Policy 40, 119-128 (2013)

Park, A., Wang, S.: China's poverty statistics. China Econ. Rev. 12, 384-398 (2001)

Ravallion, M.: Are there lessons for Africa from China's success against poverty? World Dev. 37(9), 303-313 (2009)

Ravallion, M.: On multidimensional indices of poverty. J. Econ. Inequal. 9(9), 235-248 (2011)

Ravallion, M., S. Chen: Chinas (uneven) progress against poverty. J. Dev. Econ., 82(1): 1-42 (2007)

Ray, R., Mishra, A.: Multi-dimensional deprivation in the awakening giants: A comparison of China and India on micro data. J. Asian Econ. 23(3), 454-465 (2012)

Roodman, D.: Estimating fully observed recursive mixed-process models with cmp. Stata J. 11(9), 159-206 (2011)

Roope, L., Peters, S.: Intertemporal poverty in Great Britain. Economics Discussion Paper Series 1327, University of Manchester (2013)

Sato, H.: Growth of villages in China, 1990-2002. Front. Econ. China 5(1), 135-149 (2010) 
Shimokawa, S.: When does dietary knowledge matter to obesity and overweight prevention? Food Policy 38, $35-46(2013)$

Song, Y.: Poverty reduction in China: The contribution of popularizing primary education. China World Econ. 20(1), 105-122 (2012)

Strauss, J., Thomas, D.: Health, nutrition, and economic development. J. Econ. Lit. 36, 766-817 (1998)

Tsui, K.: Multidimensional poverty indices. Soc. Choice Welf. 19(1), 69-93 (2002)

Wan, G., Zhang, Y.: Chronic and transient poverty in rural China. Econ. Lett. 119(2), 284-286 (2013)

Wang, X., Weaver, N., You, J.: The social security function of agriculture in China. J. Int. Dev. 25(1), 1-10 (2013)

World Bank: From poor areas to poor people: China's evolving poverty reduction agenda (2009)

You, J.: Risk, under-investment in agricultural assets and dynamic asset poverty in rural China. China Econ. Rev. 29, 27-45 (2014)

You, J.: Asset-based poverty transition and persistence in rural China. Agricultural Economics, forthcoming (2016)

You, J., Imai, K., Gaiha, R.: Declining nutrient intake in a growing China: Does household heterogeneity matter? World Dev. 77, 171-191 (2016)

Zhai, F.Y., Du, S.F., Wang, Z.H., Zhang, J.G., Du, W.W., Popkin, B.M.: Dynamics of the Chinese diet and the role of urbanicity, 1991-2011. Obes. Rev. 15(suppl. 1), 16-26 (2014)

Zhao, M., Konishi, Y., Glewwe, P.: Does information on health status lead to a healthier lifestyle? Evidence from China on the effect of hypertension diagnosis on food consumption. J. Health Econ. 32, 367-385 (2013)

Zheng, B.: Measuring chronic poverty: a gravitational approach Department of Economics. University of Colorado, Denver (2011)

Zhu, Y., Wu, Z., Wang, M., Du, Y., Cai, F.: Do migrants really save more? The impact of remittances on savings in rural China. J. Dev. Stud. 48(4), 654-672 (2012)

Zimmerman, F.J., Carter, M.R.: Asset smoothing, consumption smoothing and the reproduction of inequality under risk and subsistence constraints. J. Dev. Econ. 71(9), 233-260 (2003) 